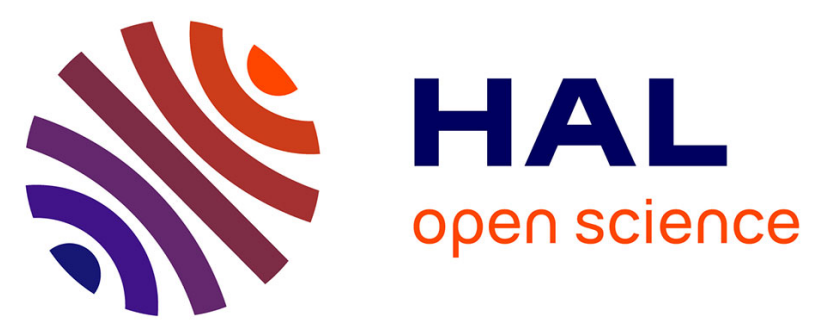

\title{
Sensitivity of the wheel-rail contact interactions and Dang Van Fatigue Index in the rail with respect to irregularities of the track geometry
}

Alfonso Panunzio, Guillaume Puel, R. Cottereau, Samuel Simon, Xavier Quost

\section{- To cite this version:}

Alfonso Panunzio, Guillaume Puel, R. Cottereau, Samuel Simon, Xavier Quost. Sensitivity of the wheel-rail contact interactions and Dang Van Fatigue Index in the rail with respect to irregularities of the track geometry. Vehicle System Dynamics, 2018, 56 (11), pp.1768-1795. 10.1080/00423114.2018.1436717 . hal-01861346

\section{HAL Id: hal-01861346 \\ https://hal.science/hal-01861346}

Submitted on 24 Aug 2018

HAL is a multi-disciplinary open access archive for the deposit and dissemination of scientific research documents, whether they are published or not. The documents may come from teaching and research institutions in France or abroad, or from public or private research centers.
L'archive ouverte pluridisciplinaire HAL, est destinée au dépôt et à la diffusion de documents scientifiques de niveau recherche, publiés ou non, émanant des établissements d'enseignement et de recherche français ou étrangers, des laboratoires publics ou privés. 
To appear in Vehicle System Dynamics

Vol. 00, No. 00, Month 20XX, 1-25

\title{
Wheel-rail contact interactions and Dang Van rail fatigue index sensitivity analysis with respect to irregularities of the track geometry
}

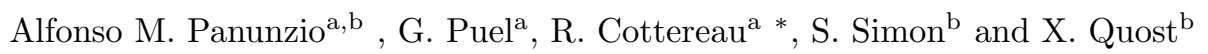 \\ ${ }^{a}$ Laboratoire MSSMat, UMR CNRS 8579, CentraleSupélec, Université Paris-Saclay \\ ${ }^{b}$ Régie autonome des transports parisiens (RATP) \\ (released month year)
}

\begin{abstract}
This paper investigates the effects of the track geometry irregularities on the wheel-rail dynamic interactions and the rail fatigue initiation through the application of the Dang Van criterion, that supposes an elastic shakedown of the structure. The irregularities are modelled, using experimental data, as a stochastic field which is representative of the considered railway network. The tracks thus generated are introduced as the input of a railway dynamics software to characterize the stochastic contact patch and the parameters on which it depends: contact forces and wheelset-rail relative position. A variance-based global sensitivity analysis is performed on quantities of interest representative of the dynamic behaviour of the system, with respect to the stochastic geometry irregularities and for different curve radius classes and operating conditions. The estimation of the internal stresses and the fatigue index being more time-consuming than the dynamical simulations, the sensitivity analysis is performed through a metamodel, whose input parameters are the wheel-rail relative position and velocity. The coefficient of variation of the number of fatigue cycles, when the simulations are performed with random geometry irregularities, varies between 0.13 and 0.28 . In a large radius curve, the most influent irregularity is the horizontal curvature, while, in a tight curve, the gauge becomes more important.
\end{abstract}

Keywords: Track geometry irregularities, wheel-rail contact, sensitivity analysis, Dang Van fatigue criterion.

\section{Introduction}

The knowledge of the dynamic behaviour of a train is very important to ensure safety and economical operability of railway networks [1]. Indeed, the variability of the wheel-rail dynamical interactions (position and stresses of the contact patch) can lead to several harmful phenomena, such as derailment, track deterioration, rail fatigue and corrugation. These interactions depend on both train and track parameters.

Concerning the vehicle parameters, the suspensions characteristics deeply modify the body stability. The primary suspension stiffness of the rear wheelsets is the parameter to which the critical speed is most sensitive, as shown trough a sensitivity analysis in [2], while the secondary suspension has a large influence on the lateral forces absorbed by the track [3]. The influence of the inertial properties of the vehicle on the wheel-rail contact dynamics has also been evaluated, finding that the mass and the vertical moment of inertia are the most sensitive parameters with respect to the contact forces [4].

\footnotetext{
${ }^{*}$ Corresponding author. Email: regis.cottereau@centralesupelec.fr
} 
The track conditions also play an important role in railway dynamics. The effect of the sleepers and the ballast conditions on the wheel-rail contact is studied, showing that a reduction of the sleepers spacing and the ballast stiffness causes a reduction of the contact forces magnitude [5]. The rail cant angle is also an important parameter: its variation can lead to increase the risk of derailment due to an augmentation of the lateral track force [6].

Concerning the rail positions, a lot of studies about the track geometry irregularities have been carried out. The layout of a railway network is decided when a line is built according to engineering considerations. However the track evolves during its operational life for many causes, such as train loads, weather conditions, substructure variations and maintenance interventions. For this reasons, the geometry of the track needs to be constantly monitored using recording systems [7-10]. Even a small variation of the track geometry can produce large variations of the rail-wheel contact patches and forces, as experimentally described in [11]. A long-term evolution of the train dynamics is also observed when the track geometry deteriorates over time, as studied in [12] through a probabilistic approach. The variations of the contact forces acting on the rails, caused by track geometry irregularities, impact the dynamical response of the train, showing that the power spectra of the forces and the accelerations are strongly related to the track geometry [13-18]. The wheel-rail contact forces also determine the rolling contact fatigue mechanisms. The track geometry irregularities can produce contact forces variations leading to rail fatigue. For instance the track lateral irregularities can be responsible for the initiation of the surface fatigue as shown in $[19,20]$. It is also numerically and experimentally observed that the squat phenomena can be related to a particular combination of irregularities [21]. The geometry irregularities are usually modelled as random fields indexed by the track curvilinear abscissa [22-24]. By the means of the measurements, it is possible to estimate the statistical properties (probability density functions and the power spectral densities, PSD) of the track geometry and generate the irregularities as random fields. In many railway applications the irregularities are generated from the PSD as Gaussian fields [20, 22, 23, 25-27] using a spectral representation [28]. In [24, 29], they are modelled by combining the Karhunen-Love decomposition and the Polynomial Chaos expansion. The main objective of this paper is to quantify the influence of each kind of geometrical track irregularities (gauge, superelevation, horizontal alignment and vertical profile) on the rolling contact fatigue and the wheel-rail dynamic interactions. In this paper a global variance-based sensitivity analysis approach, is carried out to have an estimation of the impact of geometry irregularities for different operation scenarios. Differently from a local sensitivity analysis, which is based on the computation of the gradient of the response with respect to its parameters around a nominal value, the global sensitivity analysis quantifies the output uncertainty due to the uncertainty in the input parameters by means of indices defined in the whole input random space [30-33].

Using data from a track recording train, a model is constructed for the RATP Regional Express Network (RER) line A [29]. The main steps to build the random irregularities generator are summarized in Section 2. The numerical computation of the wheel-rail contact stresses and the fatigue index is described in Section 3. The measurements of the geometry irregularities can be directly used as input for deterministic numerical computations to simulate the passage of the train on a real track portion [34-36]. In this work, the random generated tracks are used in a railway dynamics software, SIMPACK, using a semi-Hertzian contact model [37], to study the variability of the dynamic response. A variance-based sensitivity analysis [31] is performed to quantify the impact of each irregularity on the variability of some dynamical quantities of interest in a track portion (Section 4). This study is performed for different operational conditions (train load and 
velocity) and track curve radius classes.

When the rail is subjected to high surface contact stresses overtaking the steel plastic limit, corresponding to a wheel passage, its micro-structure and geometry evolve at each load cycle $[38,39]$. The rail response consists in adapting to these surface stresses by means of its elastic and plastic deformations. When the load increases above the elastic limit, the contact stresses exceed yield and the material deforms plastically [40-42].

Using the surface stresses calculated in the previous step as boundary condition, a finite element calculation allows to compute the stresses inside the rail in a fixed location of the spatial domain. Using the algorithm proposed in [43], the stresses corresponding to the steady state (i.e. when the plastic strain field is stabilized) are obtained. Finally, the Dang Van multi-axial fatigue criterion [44], chosen as quantity of interest, is applied on them. This criterion is based on the assumption of elastic shakedown of the structure, that occurs for relative low friction coefficient and surface stresses [45]. This criterion does not take into account the interaction and the competition between the wear rate and the fatigue initiation, that is usually evaluated using the wear number parameter $[46,47]$ or the distribution of plastic shear strain [48]. The rail fatigue represents a major issue on the modern railway network. Recent researches have been carried out to evaluate the influence of the composition and heat treatment [49], the internal defects shape [50], the surface stress gradient [51], the relationship with the grinding maintenance operations [52] and the heterogeneity in the materials [53]. In this work, the purpose is to understand the influence of the geometrical irregularities of the track (Section 5).

The computation of the internal stresses is far more time consuming (about 1000 times more) than the dynamical simulations. For this reason, at this stage, a metamodel is constructed, whose inputs are the wheel-rail relative position and velocity. The metamodel is constructed with a smaller number of deterministic solver runs and allows the exploration of the input random space making the Monte Carlo almost inexpensive.

\section{Track irregularities random model}

The available data from the measurement campaigns, concerning the RER line A, are processed in order to obtain realizations of the fields indexed by the curvilinear abscissa, $s$, which are commonly used to represent the track geometry:

- Gauge, $G(s)$, the spacing of the rails measured between the inner faces

- Superelevation, $E(s)$, the difference in height between the two rails

- Horizontal curvature, $H(s)$, referred to the track median line

- Vertical curvature, $V(s)$, referred to the track median line

The irregularities are defined as the differences between the measurements and the corresponding design (or theoretical) known values. The irregularities fields thus defined are centred and decorrelated from the horizontal layout of the track. The construction and the validation of the random model is described in [29]. The main steps are here reported.

Let $(\Theta, \mathcal{F}, P)$ be a probability space. Using the Karhunen-Loève expansion (KLE, [54]), a random field $f(s, \theta)$ (that could correspond to any irregularities), with $\theta \in \Theta$, is approximated by its projection on an orthogonal basis. Therefore it is expressed as a truncated sum of $M$ deterministic spatial functions $\Phi_{i}(s)$ multiplied by random decorrelated coef- 
Table 1. Number of terms used in the random fields model. KLE truncation error $\varepsilon_{K L}=0.01$

\begin{tabular}{l|cc}
\hline No. of terms & KLE & PCE (Hermite) \\
\hline Gauge & 314 & 1001 (4 germs, degree 10) \\
Superelevation & 173 & 495 (4 germs, degree 8$)$ \\
Horizontal curvature & 129 & 495 (4 germs, degree 8$)$ \\
Vertical Curvature & 100 & 330 (4 germs, degree 7$)$ \\
\hline
\end{tabular}

ficients $\eta_{i}(\theta)$ whose variance is equal to one:

$$
f(s, \theta) \approx \sum_{i=1}^{M} \sqrt{\lambda_{i}} \Phi_{i}(s) \eta_{i}(\theta)
$$

where $\Phi_{i}(s)$ and $\lambda_{i}$ are the eigenfunctions and the eigenvalues of the covariance function.

Then, the multivariate probability density functions of the random coefficients $\left(\eta_{i}\right)$ of the basis are modelled using the Polynomial Chaos Expansion (PCE, [55]). This consists in expressing the random variables in a sum of deterministic coefficients $\beta_{i j}$ multiplied by a basis of polynomial functions $\Psi_{j}$ of multivariate germs $\boldsymbol{\xi}$ whose the distribution is chosen:

$$
\eta_{i}(\theta) \approx \sum_{j=1}^{N} \beta_{i j} \Psi_{j}(\boldsymbol{\xi}(\theta))
$$

The germs distribution determines the polynomial family used as basis, which is orthogonal with respect to the germs distribution. In this work Gaussian germs and so Hermite polynomials are employed. Finally, by generating $\nu$ germs $\boldsymbol{\xi}$ it is possible to obtain $\nu$ independent realisations of the generated field $f_{\text {gen }}(s)$ by combining KLE and PCE:

$$
f_{\text {gen }}(s, \theta)=\sum_{i=1}^{M} \sum_{j=1}^{N} \sqrt{\lambda_{i}} \Phi_{i}(s) \beta_{i j} \Psi_{j}(\boldsymbol{\xi}(\theta))
$$

The number of parameters in the model, for a given KLE truncation error, is shown in Table 1. Some measured and generated realizations of the fields are shown in Fig. 1.
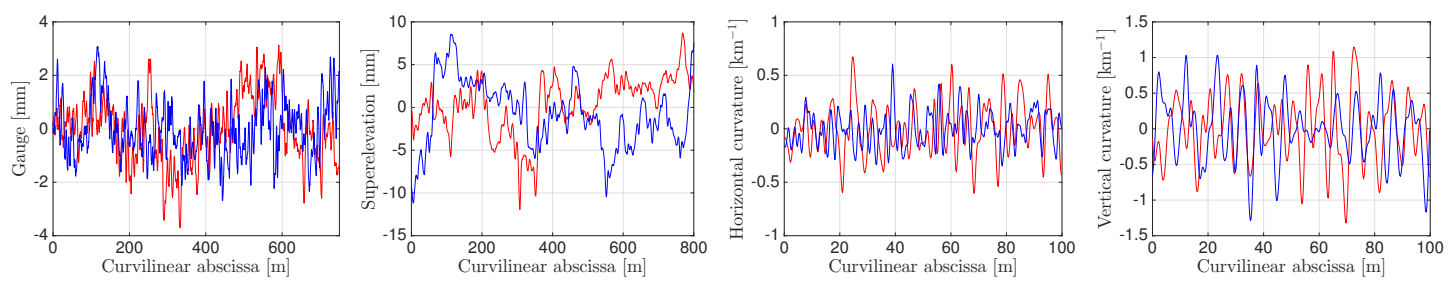

Figure 1. Example of geometry irregularities, from left: gauge, superelevation, horizontal curvature and vertical curvature. Measurements (red line), generations (blue line).

The model is representative of the considered railway line: the spatial dependency and the probability density functions are captured. The matching between the measured and the generated tracks and the model validation through dynamical simulations are described in [29]. 


\section{Numerical computation of the fatigue criterion}

In this section the main steps leading to the estimation of the fatigue criterion are highlighted. The uncertainties are not considered at this stage.

The numerical computation of the rail fatigue criterion is decomposed into three calculations steps. The first one corresponds to the simulation of the passage of a train on a track affected by geometrical irregularities. Then the stresses on the surface of the rail are used as boundary condition for a finite element computation of the rail internal stresses. At the end a multi-axial fatigue criterion is applied on these stresses.

\subsection{Dynamical computation of the rail-wheel contact stresses}

The vehicle used in the simulations is the ZRBX passenger car of the MI2N train operating on the RER line A. The passage of the vehicle on a track portion is simulated by using a railway dynamics software (SIMPACK). The vehicle is modelled as a rigid multi-bodies system representing the passenger coach, two bogies and four wheelsets. The bodies are connected by linkages representing the articulations and the suspensions, whose some features are nonlinear.

To characterize the contact patch in a point of the track, an advanced semi-Hertzian contact model [37] is used in the simulations. In this model the rail profile is discretized in strips along the lateral direction. Then, in each strip, the contact problem is solved as Hertzian. In order to take into account the rail plasticity, the contact stresses are limited and the shape of the contact zone is slightly modified [56].

Let $\mathcal{D}$ be the rail structure domain and $\mathcal{S}$ be the rail surface domain $(\mathcal{S} \subset \mathcal{D})$, as sketched in Fig. 2. The wheel-rail contact forces and stress tensor $\overline{\overline{\Sigma_{\mathcal{S}}}}(\mathbf{x}, s)$, with $\mathbf{x}=\left[x_{1}, x_{2}, x_{3}\right] \in \mathcal{S}$, are computed at each time integration step (that corresponds to a track curvilinear abscissa $s \in[0, S]$ with $S$ being the length of the track) of the nonlinear system obtained by assembling the vehicle multi-bodies model and the track.

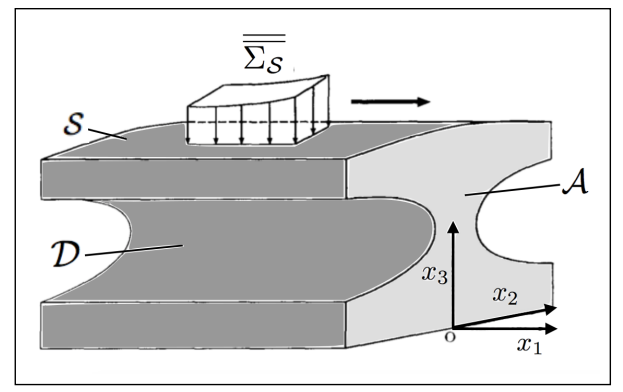

Figure 2. Rail subjected to surface contact stresses, from [44].

Using the formulation described above, the contact stresses entirely depend on the wheel-rail relative position and velocity in each strip. Since the rail profile and the friction coefficient are constant and the wheel is perfect solid of revolution (no wheel defects are considered), the wheel rotational angle and the track curvilinear abscissa are not involved in this computation. At this stage, the rails and the wheelset are considered as rigid bodies. The parameters, expressed in the rail reference frame, on which the computation of the contact stresses depends, are listed below and shown in Fig. 3:

(1) $y(s)$ Wheelset-rail lateral relative position.

(2) $z(s)$ Wheelset-rail vertical relative position. 
(3) $\dot{x}(s)$ Wheelset longitudinal velocity.

(4) $\dot{y}(s)$ Wheelset lateral velocity.

(5) $\dot{z}(s)$ Wheelset vertical velocity.

(6) $\psi(s)$ Wheelset-rail yaw angle.

(7) $\phi(s)$ Wheelset-rail roll angle.

(8) $\dot{\psi}(s)$ Wheelset-rail yaw rate.

(9) $\dot{\phi}(s)$ Wheelset-rail roll rate.

(10) $\dot{\omega}(s)$ Wheelset-rail rotational rate.

with $s$ being the track curvilinear abscissa. These parameters and the wheel-rail surface contact stresses are the outputs of this stage.

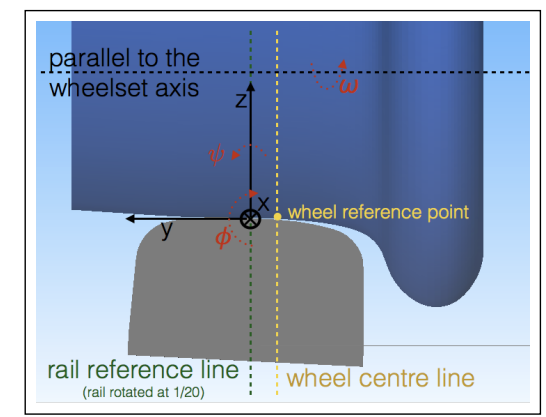

Figure 3. Wheel-rail relative position.

\subsection{Rail internal stresses computation}

The surface wheel-rail contact stresses $\overline{\overline{\Sigma_{\mathcal{S}}}}\left(\mathbf{x}, s_{i}\right)$, computed at a given track curvilinear abscissa $s_{i} \in[0, s]$, are used as boundary condition of a Finite Element computation of the internal rail stresses, acting on the domain $\mathcal{D}$ (Fig. 2), resulting from the passage of the wheel [44].

Two main hypotheses are made:

- The surface contact stress field $\overline{\overline{\Sigma_{\mathcal{S}}}}\left(\mathbf{x}, s_{i}\right)$ is stationary and is moving on the rail at constant velocity. A load cycle corresponds to a passage of this stress field on the rail.

- The rail is infinitely long along the longitudinal direction $x_{1}$.

These hypotheses imply that each rail transversal section, $\mathcal{A} \subset \mathcal{D}$, is subjected to the same load cycle and the time variable and the longitudinal spatial coordinate $x_{1}$ are equivalent [44]. For simplicity the longitudinal coordinate is replaced by the time $t$ :

$$
\overline{\overline{\Sigma_{\mathcal{S}}}}\left(\mathbf{x}, s_{i}\right)=\overline{\overline{\Sigma_{\mathcal{S}}}}\left(\mathbf{x}_{a}, t, s_{i}\right)
$$

with $\mathbf{x}_{a}=\left[x_{2}, x_{3}\right] \in \mathcal{A}$ and $t=x_{1}$.

The rail material plasticity behaviour is considered by using a bilinear stress-strain law (Fig. 4). At each passage of the load, the plastic strain tensor varies. After a different number of passages a steady state during repeated rolling-sliding is reached. This steady state corresponds to the condition according to which the plastic deformation does not change after another passage:

$$
\int \dot{\bar{\epsilon}}_{p}\left(\mathbf{x}_{a}, t, s_{i}\right) \mathrm{d} t=0
$$




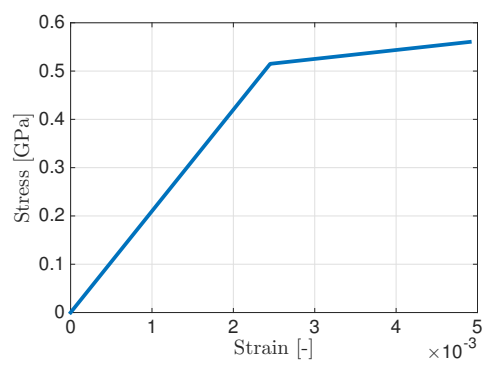

Figure 4. Bilinear stress-strain law.

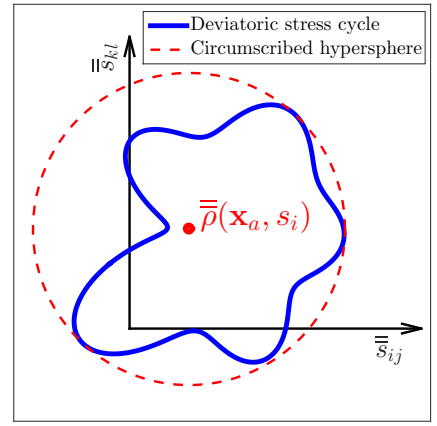

Figure 5. Centre of the smallest hypersphere circumscribed to the macroscopic stress deviator: 2D representation.

where $\overline{\bar{\epsilon}}_{p}\left(\mathbf{x}_{a}, t, s_{i}\right)$ is the plastic strain tensor, $\mathbf{x} \in \mathcal{A}$.

The internal stresses in the rail transversal section corresponding to the steady state, $\overline{\bar{\Sigma}}\left(\mathbf{x}_{a}, t, s_{i}\right)$, are therefore used for the computation of the fatigue criterion.

\subsection{Dang Van fatigue criterion}

The steady state stress cycle in the rail section $\overline{\bar{\Sigma}}\left(\mathbf{x}_{a}, t, s_{i}\right)$, computed in Section 3.2, is used for the application of the Dang Van fatigue criterion [43]. This is a multi-axial fatigue criterion based on the passage from the macroscopic to the mesoscopic scale. When the material is isotropic, the mesoscopic stress tensor $\overline{\bar{\sigma}}\left(\mathbf{x}_{a}, t, s_{i}\right)$ is calculated as:

$$
\overline{\bar{\sigma}}\left(\mathbf{x}_{a}, t, s_{i}\right)=\overline{\bar{\Sigma}}\left(\mathbf{x}_{a}, t, s_{i}\right)-\overline{\bar{\rho}}\left(\mathbf{x}_{a}, s_{i}\right)
$$

where $\overline{\bar{\Sigma}}\left(\mathbf{x}_{a}, t, s_{i}\right)$ is the macroscopic stress tensor and $\overline{\bar{\rho}}\left(\mathbf{x}_{a}, s_{i}\right)$ is the centre of the smallest hypersphere circumscribed to the macroscopic stress deviator, $\overline{\bar{s}}\left(\mathbf{x}_{a}, t, s_{i}\right)$, temporal cycle, as sketched in Fig. 5 in two dimensions.

Then the maximal shear stress is calculated as:

$$
\tau\left(\mathbf{x}_{a}, t, s_{i}\right)=\frac{1}{2}\left(\sigma_{1}\left(\mathbf{x}_{a}, t, s_{i}\right)-\sigma_{3}\left(\mathbf{x}_{a}, t, s_{i}\right)\right)
$$

where $\sigma_{1}\left(\mathbf{x}_{a}, t\right)$ and $\sigma_{3}\left(\mathbf{x}_{a}, t\right)$ are respectively the highest and the lowest principal mesoscopic stresses.

Finally the fatigue index $I\left(\mathbf{x}_{a}, s_{i}\right)$ is defined as:

$$
I\left(\mathbf{x}_{a}, s_{i}\right)=\max _{t}\left(\frac{\tau\left(\mathbf{x}_{a}, t, s_{i}\right)}{b-a h\left(\mathbf{x}_{a}, t, s_{i}\right)}\right)
$$


where $a$ and $b$ are material constants (coming from the torsion and traction fatigue tests) and $h\left(\mathbf{x}_{a}, t, s_{i}\right)$ is the mesoscopic hydrostatic pressure:

$$
h\left(\mathbf{x}_{a}, t, s_{i}\right)=\frac{1}{3} \operatorname{Tr}\left(\overline{\bar{\sigma}}\left(\mathbf{x}_{a}, t, s_{i}\right)\right)
$$

The fatigue index represents the maximal value among all the intercepts $b^{*}$ of the lines passing through the load cycle and the zero of the Dang Van line $(\tau+a h=b)$, normalized by the constant $b$, as sketched in Fig. 6. If the index is larger than 1, the structure is subject to fatigue. The largest the index is, the fewer load cycles the structure can be subjected to.

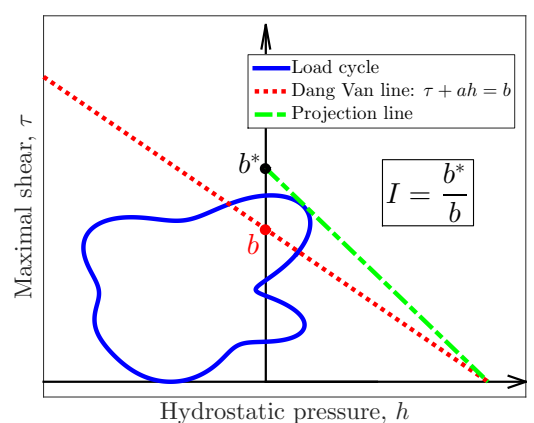

Figure 6. Dang Van fatigue criterion representation.

The Dang Van fatigue criterion supposes the elastic shakedown of the structure, i.e. after a number of load cycles no more plastic deformations occur. In a railway context, this situation is not always reached. When the plastic shakedown occurs (plastic deformation steady cycles), this regime leads to surface shelling which concerns low cycles fatigue. A shakedown map, established in [45] and illustrated in Figure 7, defines different shakedown regions, according to the friction coefficient and the wheel load parameter (ratio between the maximal stress pressure and the yield shear stress), corresponding to elastic and plastic shakedown. In this work the considered shakedown is elastic. Indeed, the friction coefficient is chosen to be equal to 0.3. The wheel load parameter depends on the contact surface stresses, that, by the contact model employed in this work are limited to take into account the elastic limit [56]. Taking a shear yield stress of around $450 \mathrm{MPa}$, the load parameter rarely exceeds the value of 2.5 . Therefore, the frame of this work concerns the elastic shakedown of the structure.

The Dang Van criterion is based on the LinTaylor homogenization assumption [57] in order to relate mesoscopic and macroscopic mechanical stress fields (Eqn. 6), by considering a plastic inclusion in an elastic matrix to express the macroscopic stress at the grain scale. In some situations, the rail microstructure plastic deformation plays an important role on the fatigue initiation [58]. In these cases the Dang Van criterion application does not match the observations. Some adaptation of the Dang Van criterion have been proposed in the literature by calibrating the criterion with respect to fatigue tests [59] and by considering a model of the plasticity for the grains [60]. However, in the case of high surface tangential stresses, surface plastic flow can be severe, making the wear phenomena predominant on the fatigue. A method developed in [46] combines the wear number (which is the product of the tangential forces and the local creepages), a quantity representative of the wear rate, in the contact patch with a non-linear damage function to estimate a fatigue index. 


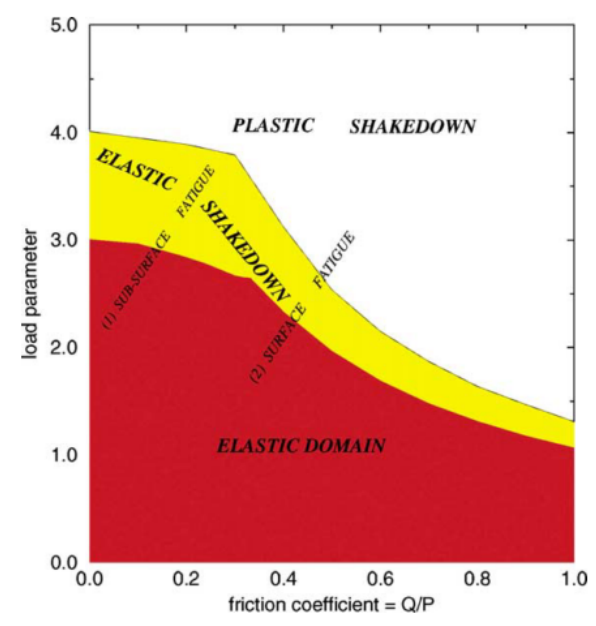

Figure 7. Shakedown map [45].

The effects of the wear on the rail surface and the plasticity at the microstructural scale are not considered in this work. The Dang Van criterion will be chosen as quantity of interest for the sensitivity analysis.

The Dang Van index can be related to the number of life cycles [61] by means of the material Wöhler curve (Fig. 8) that links the number of cycles to an equivalent alternating twist stress amplitude $\sigma_{a}$ which is related to the fatigue index:

$$
\sigma_{a}\left(\mathbf{x}_{a}, s_{i}\right)=I\left(\mathbf{x}_{a}, s_{i}\right) b
$$

In this paper, a parametrization of the Wöhler curve is chosen to express the number life cycles at a given position on the track $C\left(s_{i}\right)$ as:

$$
C\left(s_{i}\right)=\min _{\mathbf{x}_{a}}\left(\left\{\begin{array}{ll}
\frac{c}{b\left(I\left(\mathbf{x}_{a}, s_{i}\right)-1\right)} & \text { if } I\left(\mathbf{x}_{a}, s_{i}\right)>1 \\
\infty & \text { if } I\left(\mathbf{x}_{a}, s_{i}\right) \leq 1
\end{array}\right)\right.
$$

with $c$ being a material constant.

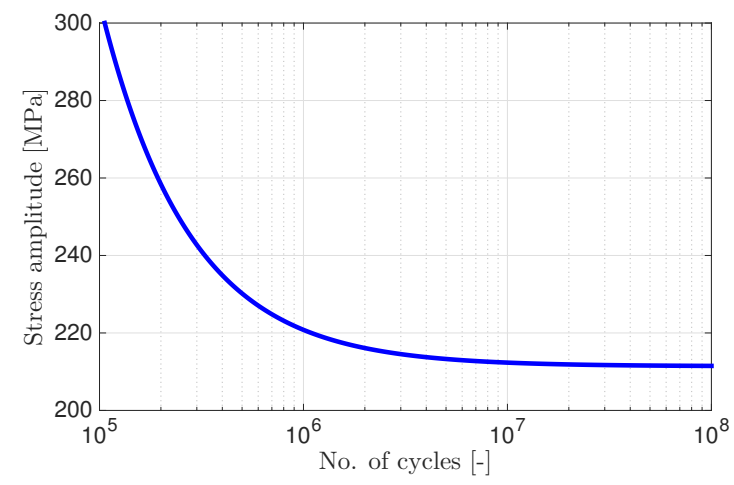

Figure 8. Wöhler curve of the rail material. 


\section{Sensitivity analysis on the vehicle dynamics}

In this section the track geometry irregularities are considered as random fields in order to perform a sensitivity analysis on quantities of interest related to the train dynamics.

\subsection{Dynamical computation of the rail-wheel contact forces and kinematic parameters}

The tracks randomly generated are introduced as inputs the railway dynamics software used to compute the rail-wheel contact stresses. Only the track geometry, described in Section 2, is stochastic. The rail profile (UIC60) is considered as theoretical (the wear is not included) and the friction coefficient varies neither along the rail profile nor along the curvilinear abscissa of the track. All the vehicle parameters are deterministic (manufacturer data).

Since the dynamical simulations are not heavily time-consuming (around 1 minute for a simulation of a $100 \mathrm{~m}$ track portion), the random space, i.e. the germs $\boldsymbol{\xi}(\theta)$ in Equation (3), is explored through Monte Carlo sampling (MCS), in which each simulation corresponds to a generated track geometry. Let $\mathbf{u}=\mathbf{u}(s, \theta)$ be the multi-dimensional random fields representing the evolution of the kinematic parameters, listed in Section 3.1. When all the input parameters of the dynamical simulations are stationary in the space, the field $\mathbf{u}$ is stationary, i.e. its statistics are invariants by translation:

$$
\begin{aligned}
& p_{\theta}\left(\mathbf{u}\left(s_{1}+s^{\prime}, \theta\right), \ldots, \mathbf{u}\left(s_{n}+s^{\prime}, \theta\right)\right)= \\
& p_{\theta}\left(\mathbf{u}\left(s_{1}, \theta\right), \ldots, \mathbf{u}\left(s_{n}, \theta\right)\right)
\end{aligned}
$$

where $p_{\theta}\left(\mathbf{u}\left(s_{1}, \theta\right), \ldots, \mathbf{u}\left(s_{n}, \theta\right)\right)$ is the marginal probability density function of order $n$ of the random field $\mathbf{u}(s, \theta)$.

The stationarity implies that the Sobol sensitivity indices related to the quantities of interest do not depend on the position on the track.

\subsection{Vehicle dynamics quantities of interest}

Some quantities of interest $(\mathrm{QoI})$ are chosen as representative of the dynamic wheel-rail interaction:

- $y$. Leading wheel-rail lateral relative position (outer rail if curved track).

- $z$. Leading wheel-rail vertical relative position (outer rail if curved track).

- $\psi_{W S}$. Yaw angle of the leading wheelset.

- $Y$. Leading wheel-rail lateral force (outer rail if curved track).

- $Q$. Leading wheel-rail vertical force (outer rail if curved track).

- $\sum Y$. Sum of the lateral contact forces on the leading bogie.

At this stage the first order sensitivity indices are calculated via Monte Carlo sampling using the technique proposed in [32]. Their convergence has been validated by bootstrapping [62].

In most of the dynamical simulations, the outputs are usually filtered according to the norm EN14363 [63]. The dynamical outputs, in this work, are not filtered according to this norm, which indicates a low-pass filter at $20 \mathrm{~Hz}$ for the contact forces. In the spatial 
frequency domain, this cut-off frequency corresponds, for the velocities of $120 \mathrm{~km} / \mathrm{h}$ and $80 \mathrm{~km} / \mathrm{h}$, to $0.6 \mathrm{~m}^{-1}$ and $0.9 \mathrm{~m}^{-1}$ respectively. The Nyquist frequency of inputs random irregularities fields is $2 \mathrm{~m}^{-1}$. This frequency has been chosen for the dynamical outputs. However, the spectral power at the frequencies higher than $1 \mathrm{~m}^{-1}$ (the PSDs of random fields are shown in [29] represents less than $0.1 \%$ of the total variance of the fields. Their influence on the global sensitivity indices of the dynamical quantities is weak. The indices do not vary significantly if the filters indicated in the norm EN14363 are applied.

\subsection{Global sensitivity indices}

A variance-based global sensitivity analysis [31, 64] is performed, with respect to the stochastic geometry irregularities on a track portion. The aim is to identify which kinds of irregularities have the most important impact on the contact patch variations. The Sobol sensitivity analysis allows to evaluate the main impact of each input parameter and the interactions between the inputs which produce important variations on the quantities of interest. $Q$ :

The indices are based on the decomposition of the variance $V$ of the quantity of interest

$$
\begin{aligned}
& V=\operatorname{Var}[Q]=\sum_{i=1}^{d} V_{i}+\sum_{i<j}^{d} V_{i j}+\cdots+V_{12 \ldots d} \\
& V_{i j \ldots k}=\operatorname{Var}_{\left(z_{i}, z_{j}, \ldots, z_{k}\right)}\left[\mathbb{E}_{\mathbf{Z}_{\sim i j \ldots k}}\left[Q \mid z_{i}, z_{j}, \ldots, z_{k}\right]\right]
\end{aligned}
$$

where $\mathbf{Z}=\left[z_{1}, \ldots, z_{d}\right]$ is the input random vector of dimension $d, \mathbf{Z}_{\sim i j \ldots k}$ indicates all the components of $\mathbf{Z}$ but $i, j, \ldots, k$ and $Q \mid z_{i}, z_{j}, \ldots, z_{k}$ represents the quantity of interest $Q$ conditioned to $z_{i}, z_{j}, \ldots, z_{k}$.

The Sobol index of the quantity $Q$, concerning the random variables $z_{i}, z_{j}, \ldots, z_{k}$, is defined as:

$$
S_{i j \ldots k}=\frac{V_{i j \ldots k}}{V}
$$

The index order is the number of inputs with whom the index is associated.

In this work, the random vector $\mathbf{Z}$ in Eqn. (13) is the vector collecting the germs $\boldsymbol{\xi}$, in Eqn. (3), related to all the irregularities fields. Note that, as indicated in Table 1, each field is generated by 4 germs. This means that when a sensitivity index is defined with respect to one irregularity field, it is related to the 4 germs that generate it.

\subsection{Results}

The sensitivity analysis is performed for different operating scenarios, that are listed in Table 2. These are typical scenarios on the considered railway network for which the random model of the irregularities has been constructed. A passenger load equal to $22 \mathrm{t}$ corresponds to around 6 passengers per $\mathrm{m}^{2}$. The mean value, the coefficient of variation (ratio of the standard deviation to the mean) and the 1st order sensitivity indices are shown for each quantity of interest. 
Table 2. Operating scenarios test cases.

\begin{tabular}{ccc}
\hline Curve radius & Velocity & Passenger load \\
\hline $1000 \mathrm{~m}$ (Wide) & $80 \mathrm{~km} / \mathrm{h}$ (Slow) & $0 \mathrm{t}$ (Empty) \\
$1000 \mathrm{~m}$ (Wide) & $110 \mathrm{~km} / \mathrm{h}$ (Fast) & $0 \mathrm{t}$ (Empty) \\
$450 \mathrm{~m}$ (Tight) & $80 \mathrm{~km} / \mathrm{h}$ (Slow) & $0 \mathrm{t}$ (Empty) \\
$450 \mathrm{~m}$ (Tight) & $110 \mathrm{~km} / \mathrm{h}$ (Fast) & $0 \mathrm{t}$ (Empty) \\
$1000 \mathrm{~m}$ (Wide) & $80 \mathrm{~km} / \mathrm{h}$ (Slow) & $22 \mathrm{t}$ (Full) \\
$1000 \mathrm{~m}$ (Wide) & $110 \mathrm{~km} / \mathrm{h}$ (Fast) & $22 \mathrm{t}$ (Full) \\
$450 \mathrm{~m}$ (Tight) & $80 \mathrm{~km} / \mathrm{h}$ (Slow) & $22 \mathrm{t}$ (Full) \\
$450 \mathrm{~m}$ (Tight) & $110 \mathrm{~km} / \mathrm{h}$ (Fast) & $22 \mathrm{t}$ (Full) \\
\hline
\end{tabular}

Table 3. Mean $(\mu)$, coefficient of variation $\left(C_{V}\right)$ and 1st order Sobol indices of the wheel-rail lateral position $y$. Parameters whose indices are always smaller than 0.1 are not shown.

\begin{tabular}{|c|c|c|c|c|c|c|c|c|}
\hline & $\begin{array}{l}\text { Wide } \\
\text { Slow } \\
\text { Empty }\end{array}$ & $\begin{array}{l}\text { Wide } \\
\text { Fast } \\
\text { Empty }\end{array}$ & $\begin{array}{l}\text { Tight } \\
\text { Slow } \\
\text { Empty }\end{array}$ & $\begin{array}{l}\text { Tight } \\
\text { Fast } \\
\text { Empty }\end{array}$ & $\begin{array}{l}\text { Wide } \\
\text { Slow } \\
\text { Full }\end{array}$ & $\begin{array}{l}\text { Wide } \\
\text { Fast } \\
\text { Full }\end{array}$ & $\begin{array}{l}\text { Tight } \\
\text { Slow } \\
\text { Full }\end{array}$ & $\begin{array}{l}\text { Tight } \\
\text { Fast } \\
\text { Full }\end{array}$ \\
\hline$\frac{\text { 毒 }}{\mathrm{z}}$ & 3.70 & 3.70 & 3.77 & 3.79 & 3.73 & 3.73 & 3.79 & 3.82 \\
\hline U & 0.02 & 0.05 & 0.00 & 0.01 & 0.02 & 0.04 & 0.00 & 0.00 \\
\hline & \multicolumn{8}{|c|}{ 1st order sensitivity indices } \\
\hline 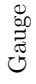 & 0.33 & 0.13 & 0.51 & 0.55 & 0.28 & 0.17 & 0.38 & 0.50 \\
\hline है & 0.63 & 0.76 & 0.43 & 0.39 & 0.69 & 0.76 & 0.55 & 0.44 \\
\hline
\end{tabular}

\subsubsection{Wheel-rail lateral position - y}

For the leading wheelsets, since the wheel is guided by the rail (the contact is localized on the wheel flange), the variation of its lateral position is very small (standard deviation smaller than $1 \mathrm{~mm}$ ), as observed in Table. 3. Although the position of the leading wheel is very stable in a curve, a small variation of the lateral position can lead to large variations of the contact forces. Indeed, because of the contact model described in Section 3.1, the contact forces and stresses entirely depend on the rail-wheel relative position and velocity. Even, when the standard deviation of the lateral position is smaller than $0.1 \mathrm{~mm}$, this parameter is strongly correlated (around 0.9) with the contact lateral force. When the curve radius is the larger one, the wheel-rail relative position $y$ of the outer rail is mostly sensitive to the horizontal curvature and gauge irregularities (63\% and $33 \%$ for case A). In a tight curve, the standard deviation decreases (the contact position is more stable) and the importance of the gauge increases. When the velocity increases (this implies a larger cant deficiency), the index related to the gauge decreases in the $1000 \mathrm{~m}$ curve while increases in the $450 \mathrm{~m}$ curve.

\subsubsection{Wheel-rail vertical position - z}

The wheel-rail vertical position is sensitive to the superelevation irregularities in all the cases (Table 4). The variability of this parameter is small: the coefficient of variation varies between 0.05 and 0.08 . Note that this quantity, in a curved track, is correlated to the wheel-rail lateral position. In fact, when the wheel moves towards the rail, it tends to rise on the rail. Because of this correlation, this parameter is also sensitive to the 
Table 4. Mean $(\mu)$, coefficient of variation $\left(C_{V}\right)$ and 1 st order Sobol indices of the wheel-rail vertical position $z$. Parameters whose indices are always smaller than 0.1 are not shown.

\begin{tabular}{|c|c|c|c|c|c|c|c|c|}
\hline & $\begin{array}{l}\text { Wide } \\
\text { Slow } \\
\text { Empty }\end{array}$ & $\begin{array}{l}\text { Wide } \\
\text { Fast } \\
\text { Empty }\end{array}$ & $\begin{array}{l}\text { Tight } \\
\text { Slow } \\
\text { Empty }\end{array}$ & $\begin{array}{l}\text { Tight } \\
\text { Fast } \\
\text { Empty }\end{array}$ & $\begin{array}{l}\text { Wide } \\
\text { Slow } \\
\text { Full }\end{array}$ & $\begin{array}{l}\text { Wide } \\
\text { Fast } \\
\text { Full }\end{array}$ & $\begin{array}{l}\text { Tight } \\
\text { Slow } \\
\text { Full }\end{array}$ & $\begin{array}{l}\text { Tight } \\
\text { Fast } \\
\text { Full }\end{array}$ \\
\hline $\begin{array}{l}\vec{\Xi} \\
\text { ב्g } \\
z\end{array}$ & 0.15 & 0.15 & 0.16 & 0.16 & 0.15 & 0.14 & 0.15 & 0.15 \\
\hline$\vec{z}$ & 0.05 & 0.08 & 0.04 & 0.05 & 0.06 & 0.08 & 0.04 & 0.05 \\
\hline \multicolumn{9}{|c|}{ 1st order sensitivity indices } \\
\hline 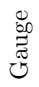 & 0.11 & 0.09 & 0.14 & 0.12 & 0.09 & 0.08 & 0.07 & 0.08 \\
\hline $\begin{array}{l}\overrightarrow{0} \\
\vec{d} \\
\dot{D}\end{array}$ & 0.62 & 0.51 & 0.74 & 0.77 & 0.63 & 0.56 & 0.84 & 0.82 \\
\hline$\stackrel{\vec{Z}}{\stackrel{己}{0}}$ & 0.26 & 0.40 & 0.09 & 0.09 & 0.27 & 0.36 & 0.07 & 0.07 \\
\hline
\end{tabular}

horizontal curvature (1000 $\mathrm{m}$ radius curve) and the gauge (450 radius curve).

\subsubsection{Wheelset yaw angle $-\psi_{W S}$}

Table 5. Mean $(\mu)$, coefficient of variation $\left(C_{V}\right)$ and 1 st order Sobol indices of the wheelset yaw angle $\psi_{W S} . \mathrm{Pa}$ rameters whose indices are always smaller than 0.1 are not shown.

\begin{tabular}{|c|c|c|c|c|c|c|c|c|}
\hline & $\begin{array}{l}\text { Wide } \\
\text { Slow } \\
\text { Empty }\end{array}$ & $\begin{array}{l}\text { Wide } \\
\text { Fast } \\
\text { Empty }\end{array}$ & $\begin{array}{l}\text { Tight } \\
\text { Slow } \\
\text { Empty }\end{array}$ & $\begin{array}{l}\text { Tight } \\
\text { Fast } \\
\text { Empty }\end{array}$ & $\begin{array}{l}\text { Wide } \\
\text { Slow } \\
\text { Full }\end{array}$ & $\begin{array}{l}\text { Wide } \\
\text { Fast } \\
\text { Full }\end{array}$ & $\begin{array}{l}\text { Tight } \\
\text { Slow } \\
\text { Full }\end{array}$ & $\begin{array}{l}\text { Tight } \\
\text { Fast } \\
\text { Full }\end{array}$ \\
\hline$\underset{2}{\sigma}$ & 0.13 & 0.09 & 0.32 & 0.21 & 0.13 & 0.10 & 0.33 & 0.22 \\
\hline$\vec{\partial}$ & 0.21 & 0.32 & 0.09 & 0.13 & 0.21 & 0.29 & 0.09 & 0.12 \\
\hline \multicolumn{9}{|c|}{ 1st order sensitivity indices } \\
\hline 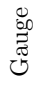 & 0.24 & 0.24 & 0.23 & 0.24 & 0.24 & 0.24 & 0.23 & 0.24 \\
\hline تِّتِ & 0.70 & 0.70 & 0.68 & 0.66 & 0.72 & 0.72 & 0.69 & 0.67 \\
\hline
\end{tabular}

Concerning the yaw angle, which is not null for the leading wheelsets, the variations are mostly influenced by the horizontal curvature followed by the gauge in each case as shown in Table 5 . The mean value is higher in the tighter curve and when the vehicle runs at the smallest velocity while the coefficient of variation tends to be larger in a wide curve.

\subsubsection{Leading outer rail lateral force - $Y$}

The lateral effort on the outer rail $Y$ is strongly correlated to the lateral position $y$ in a curved track. The most sensitive irregularities are still the horizontal curvature (1000 
Table 6. Mean $(\mu)$, coefficient of variation $\left(C_{V}\right)$ and 1st order Sobol indices of the leading outer rail lateral force

$Y$. Parameters whose indices are always smaller than 0.1 are not shown.

\begin{tabular}{|c|c|c|c|c|c|c|c|c|}
\hline & $\begin{array}{l}\text { Wide } \\
\text { Slow } \\
\text { Empty }\end{array}$ & $\begin{array}{l}\text { Wide } \\
\text { Fast } \\
\text { Empty }\end{array}$ & $\begin{array}{l}\text { Tight } \\
\text { Slow } \\
\text { Empty }\end{array}$ & $\begin{array}{l}\text { Tight } \\
\text { Fast } \\
\text { Empty }\end{array}$ & $\begin{array}{l}\text { Wide } \\
\text { Slow } \\
\text { Full }\end{array}$ & $\begin{array}{l}\text { Wide } \\
\text { Fast } \\
\text { Full }\end{array}$ & $\begin{array}{l}\text { Tight } \\
\text { Slow } \\
\text { Full }\end{array}$ & $\begin{array}{l}\text { Tight } \\
\text { Fast } \\
\text { Full }\end{array}$ \\
\hline$\underset{z}{Z_{2}}$ & 11.91 & 14.79 & 17.25 & 25.81 & 16.62 & 20.89 & 24.10 & 35.95 \\
\hline$\vec{U}$ & 0.25 & 0.28 & 0.16 & 0.16 & 0.21 & 0.24 & 0.11 & 0.13 \\
\hline \multicolumn{9}{|c|}{ 1st order sensitivity indices } \\
\hline 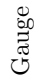 & 0.42 & 0.37 & 0.63 & 0.65 & 0.36 & 0.36 & 0.52 & 0.61 \\
\hline$\underset{ت}{0}$ & 0.55 & 0.58 & 0.32 & 0.32 & 0.61 & 0.62 & 0.42 & 0.35 \\
\hline
\end{tabular}

m curve radius) and the gauge (450 m curve radius), Table 6 . The increases of the train velocity and weight and especially the decrease of the curve radius lead to an increase of the mean value.

\subsubsection{Leading outer rail vertical force $-Q$}

Table 7. Mean $(\mu)$, coefficient of variation $\left(C_{V}\right)$ and 1 st order Sobol indices of the leading outer rail vertical force $Q$. Parameters whose indices are always smaller than 0.1

\begin{tabular}{|c|c|c|c|c|c|c|c|c|}
\hline & $\begin{array}{l}\text { Wide } \\
\text { Slow } \\
\text { Empty }\end{array}$ & $\begin{array}{l}\text { Wide } \\
\text { Fast } \\
\text { Empty }\end{array}$ & $\begin{array}{l}\text { Tight } \\
\text { Slow } \\
\text { Empty }\end{array}$ & $\begin{array}{l}\text { Tight } \\
\text { Fast } \\
\text { Empty }\end{array}$ & $\begin{array}{l}\text { Wide } \\
\text { Slow } \\
\text { Full }\end{array}$ & $\begin{array}{l}\text { Wide } \\
\text { Fast } \\
\text { Full }\end{array}$ & $\begin{array}{l}\text { Tight } \\
\text { Slow } \\
\text { Full }\end{array}$ & $\begin{array}{l}\text { Tight } \\
\text { Fast } \\
\text { Full }\end{array}$ \\
\hline$\frac{\underset{2}{Z}}{2}$ & 71.91 & 80.08 & 74.11 & 91.92 & 100.92 & 114.01 & 103.73 & 131.65 \\
\hline$\vec{U}$ & 0.03 & 0.03 & 0.03 & 0.03 & 0.03 & 0.03 & 0.03 & 0.03 \\
\hline \multicolumn{9}{|c|}{ 1st order sensitivity indices } \\
\hline 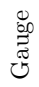 & 0.08 & 0.07 & 0.11 & 0.13 & 0.06 & 0.06 & 0.06 & 0.08 \\
\hline$\frac{\vec{d}}{\dot{d}}$ & 0.51 & 0.40 & 0.52 & 0.37 & 0.48 & 0.36 & 0.49 & 0.33 \\
\hline 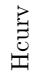 & 0.19 & 0.23 & 0.15 & 0.20 & 0.20 & 0.32 & 0.16 & 0.24 \\
\hline$\stackrel{\vec{Z}}{\overrightarrow{0}}$ & 0.13 & 0.16 & 0.12 & 0.16 & 0.13 & 0.12 & 0.12 & 0.12 \\
\hline
\end{tabular}

The most influent parameter on the vertical force $Q$ is the superelevation irregularity as shown in Table 7 . Its standard deviation is about $3 \%$ of the mean value in all the test scenarios. The projection of the weight force on the axis of $Q$ is very sensitive to the superelevation variations. In fact, because of the vertical equilibrium, an increase of the track inclination (and so the superelevation) induces an increase of the force on the outer wheel and a decrease on the inner wheel. The other geometry irregularities are less 
important but not negligible. Note that when the train velocity increases (and so the cant deficiency), the index related to the superelevation decreases.

\subsubsection{Leading Bogie lateral force $-\sum Y$}

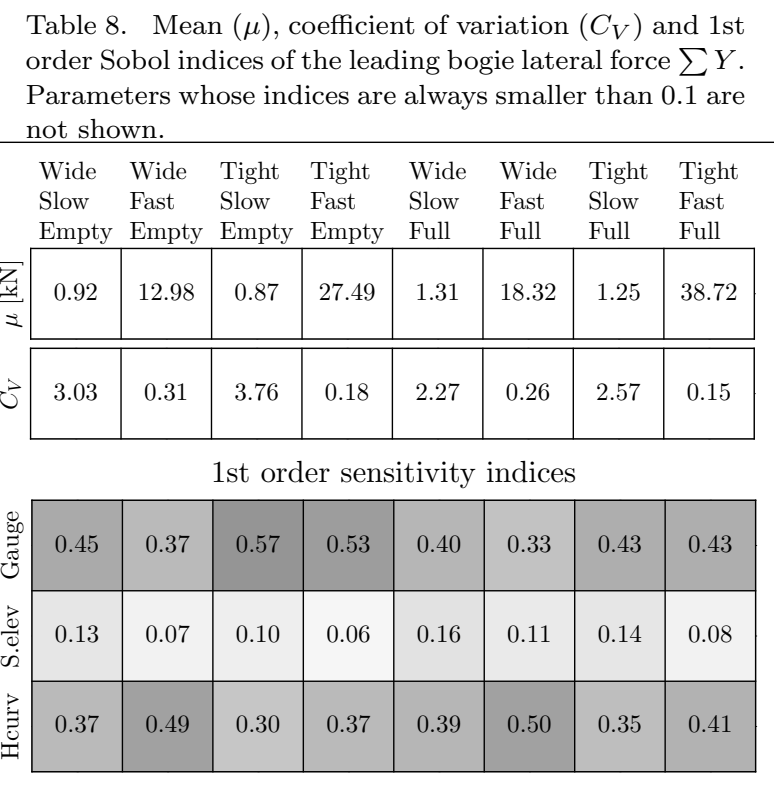

The repartition of the sensitivity indices, shown in Table 7, concerning the sum of the lateral forces on the leading bogie is more equilibrated between the horizontal curvature and the gauge irregularities. Note that, for the cases when the train runs at $80 \mathrm{~km} / \mathrm{h}$, the cant deficiency is much smaller than the other test cases. This is why the mean value is almost equal to zero in these cases: the centrifugal force on the bogie is equilibrated by the weight.

\subsubsection{Threshold exceedance on the lateral force}

In this section, the chosen quantity of interest is the overrun of a threshold $\bar{y}$ on the lateral forces $Y$. The threshold is the $10 \%$ percentile of each test cases. The quantity of interest is equal to 1 whenever the threshold is overrun, 0 elsewhere. The thresholds and the associated sensitivity indices are shown in Table 9.

The track gauge is always is most sensitive parameter, even in the case of the wide curve (where the horizontal curvature is the most sensitive parameter for the force $Y$ ). A large gauge defect can lead to large values of the lateral force. However, the importance of the horizontal curvature increases in the wide curve and is also coupled with the gauge (2nd order index).

\section{Sensitivity analysis on the rail fatigue}

The computation of the rail internal steady state stress cycle, described in Section 3.2, is the most expensive stage. A simulation lasts from 30 to 80 minutes, making the Monte Carlo sampling not advisable for exploring the random space. For this reason the computation of the internal load cycle and the application of the Dang Van fatigue index 


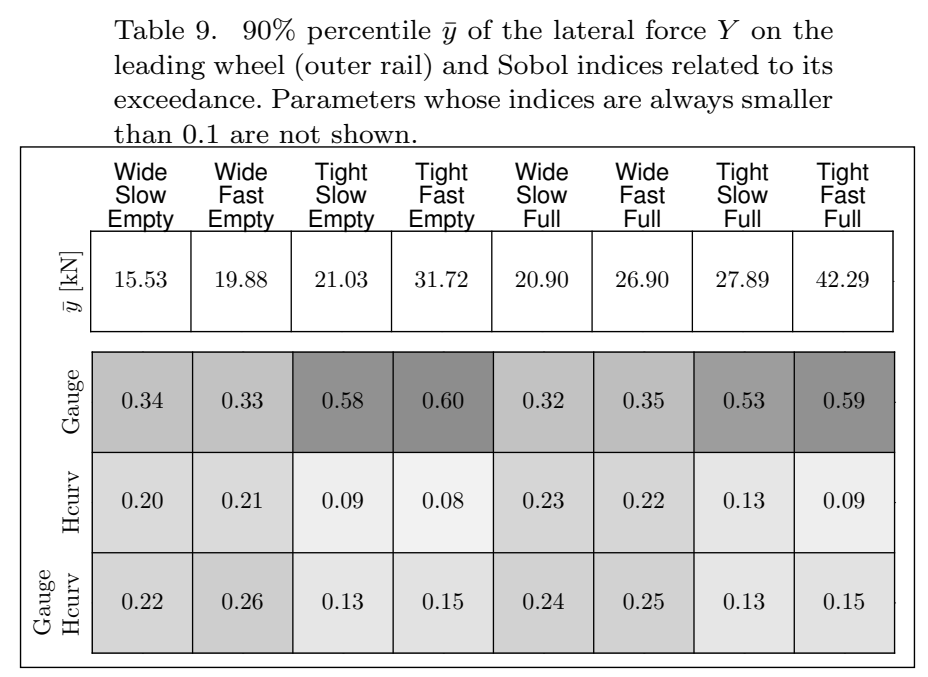

on them (Section 3.3) is replaced by a metamodel. After its construction the metamodel allows the exploration of the random space with little computational effort. In the next section the polynomial chaos based metamodel of the fatigue index is presented. Note that in Section 2 the PCE is used for modelling a random space (geometry irregularities). Here it is used for propagating uncertainties through metamodelling.

The quantity of interest at this stage is the random fatigue index defined in Eqn. (8) in the spatial domain: $I\left(\mathbf{x}_{a}, s, \theta\right)$.

\subsection{Input random space of the metamodel}

Since the mechanical properties and the structure geometry of the rail are considered as deterministic, the load cycle in the rail (and so the fatigue index) only depends on the boundary condition, i.e. the surface wheel-rail contact stresses. In the contact model described in Section 3.1, this surface contact stresses field is entirely determined by the kinematic parameters listed in Section 3.1 and grouped in the stationary random field $\mathbf{u}(s, \theta)$ introduced in Section 4.1. Therefore the field $\mathbf{u}(s, \theta)$ constitutes the input random space of the metamodel. The statistics of this random field have been estimated by Monte Carlo sampling, in which each simulation corresponds to a generated track irregularities field.

The PCE metamodel of the fatigue index is equal to:

$$
I\left(\mathbf{x}_{a}, s, \theta\right) \approx \sum_{k=1}^{T} \alpha_{k}\left(\mathbf{x}_{a}\right) \zeta_{k}(\mathbf{u}(s, \theta), s)
$$

\subsection{Polynomial Chaos Expansion basis}

The PCE basis has to be orthogonal with respect to the random space [65]:

$$
\int_{\Theta} \zeta_{k}(\mathbf{u}(s, \theta), s) \zeta_{l}(\mathbf{u}(s, \theta), s) p_{\theta}(\mathbf{u}(s, \theta)) \mathrm{d} \theta=\delta_{k l}
$$

where $\delta_{k l}$ indicates the Kronecker delta.

Because of the stationarity of $\mathbf{u}(s, \theta)$, Eqn. (12), the orthogonality condition does not 
depend on the curvilinear abscissa $s$ :

$$
\zeta_{k}(\mathbf{u}(s, \theta), s)=\zeta_{k}(\mathbf{u}(s, \theta)) \quad \forall s \in[0, S]
$$

As proposed in [66], the PCE basis, orthogonal with respect to an arbitrary multidimensional random space, can be constructed by Gram-Schmidt orthogonalization method:

$$
\begin{aligned}
\zeta_{1}(\mathbf{u}(s, \theta)) & =0 \\
\zeta_{k}(\mathbf{u}(s, \theta)) & =\frac{\widetilde{\zeta_{k}}(\mathbf{u}(s, \theta))}{<\widetilde{\zeta_{k}}(\mathbf{u}(s, \theta)), \widetilde{\zeta_{k}}(\mathbf{u}(s, \theta))>} \\
\widetilde{\zeta_{k}}(\mathbf{u}(s, \theta)) & =e_{k}(\mathbf{u}(s, \theta))-\sum_{l=1}^{k-1} c_{k l} \zeta_{l}(\mathbf{u}(s, \theta))
\end{aligned}
$$

where $2 \leq k \leq T,\langle\bullet \bullet \bullet>$ denotes the inner product of Eqn. (16) and

$$
\begin{aligned}
& e_{k}(\mathbf{u}(s, \theta))=\prod_{m=0}^{D} \mathbf{u}(s, \theta)^{k_{m}} \\
& k_{m} \in\{0, \ldots, P\} / \sum_{m=0}^{D} k_{m} \leq P \\
& c_{k l}=<e_{k}(\mathbf{u}(s, \theta)), \zeta_{l}(\mathbf{u}(s, \theta))>
\end{aligned}
$$

with $P$ and $D$ being the maximal polynomial degree and the dimension of the random field $\mathbf{u}(s, \theta)$.

\subsection{Polynomial Chaos Expansion coefficients}

The PCE coefficients $\left\{\alpha_{k}\right\}$ in Eqn. (15) are computed by least-square regression [67]. These approach minimizes the mean squared error between the prediction and the solution.

Let $\left\{\mathbf{u}\left(s_{1}, \theta_{1}\right), \ldots, \mathbf{u}\left(s_{R}, \theta_{R}\right)\right\}$ be the set collecting $R$ regression points. This set is obtained by Monte Carlo sampling $R$ realizations of the field $\mathbf{u}(s, \theta)$ at curvilinear abscissa $s$ randomly chosen in the interval $[0, S]$. Because of the stationarity of $\mathbf{u}(s, \theta)$, the choice of $s$ is completely arbitrary.

Let $\zeta$ denote the matrix whose the coefficients are given by $\zeta_{i j}=\zeta_{j}\left(\mathbf{u}\left(s_{i}, \theta_{i}\right)\right)$ with $i=1, \ldots, R$ and $j=0, \ldots, T$. Let $\mathcal{I}$ the vector containing the fatigue indices, defined in Eqn. (8), computed in the regression points: $\mathcal{I}_{k}=I\left(\mathbf{x}_{a}, s_{k}, \theta_{k}\right)$ with $k=1, \ldots, R$. The PCE coefficients are calculated as:

$$
\mathbf{A}=\left(\zeta^{\mathrm{T}} \zeta\right)^{-1} \zeta^{\mathrm{T}} \mathcal{I}
$$

where $\mathbf{A}$ is a vector such that $\mathbf{A}_{k}=\alpha_{k}\left(\mathbf{x}_{a}\right)$. Note that, with this strategy, the Monte Carlo simulations are not avoided since $R$ computations of the fatigue index are still needed to obtain the vector $\mathcal{I}$. However the number of Monte Carlo simulations that would have needed for a direct estimation of the statistics of the fatigue index would have been much 
more larger than the number of regression points $R$ used for the estimation of the PCE coefficients.

As described in [68], the use of a sparse PCE is more efficient than a complete basis PCE. The idea of the sparse PCE it to use only some polynomial functions instead of the complete basis. In this paper the PCE coefficients are firstly computed with a complete basis as described below. The 0-degree polynomial term is always selected in the sparse basis because it determines the mean value of the quantity of interest. Then, the PCE coefficients $\alpha_{k}\left(\mathbf{x}_{a}\right)$, with $k>1$, are sorted according to the descending order of their squared value. Let $\widetilde{\alpha}_{k}\left(\mathbf{x}_{a}\right)$ be the sorted PCE coefficients. The sparse PCE basis is obtained by selecting the 0 -degree polynomial term and $T^{\prime}\left(\mathbf{x}_{a}\right)$ more terms such that $T^{\prime}\left(\mathbf{x}_{a}\right)$ is the minimal number satisfying the following condition:

$$
\frac{\sum_{k=1}^{T^{\prime}\left(\mathbf{x}_{a}\right)} \widetilde{\alpha}_{k}\left(\mathbf{x}_{a}\right)^{2}}{\sum_{k=1}^{T} \alpha_{k}\left(\mathbf{x}_{a}\right)^{2}} \geq 1-\varepsilon_{s}
$$

where $\varepsilon_{s}$ is a tolerance. Then the PCE coefficients are recomputed, as in Eqn. (20), by taking only the $T^{\prime}\left(\mathbf{x}_{a}\right)$ terms satisfying the sparsity criterion and the 0-degree polynomial term. Let $\widehat{\alpha}_{k}\left(\mathbf{x}_{a}\right)$ and $\mathcal{K}\left(\mathbf{x}_{a}\right)$ indicate respectively the recomputed coefficients and the sparse indices set.

The metamodel error is evaluated by Leave-One-Out (LOO) cross-validation. Supposing that the metamodel would have been constructed with all the regression points but the $i$-th one, the difference between the deterministic solution and the metamodel prediction in the $i$-th point can be calculated. Repeating this step in all the $R$ regression points, the squared mean of these differences is the LOO error. As shown in [69], the relative LOO error, $\varepsilon_{l}\left(\mathbf{x}_{a}\right)$, can be analytically calculated as:

$$
\varepsilon_{l}\left(\mathbf{x}_{a}\right)=\frac{1}{R} \sum_{i=1}^{R}\left(\frac{I\left(\mathbf{x}_{a}, s_{i}, \theta_{i}\right)-\sum_{k \in \mathcal{K}\left(\mathbf{x}_{a}\right)} \widehat{\alpha}_{k}\left(\mathbf{x}_{a}\right) \zeta_{k}\left(\mathbf{u}\left(s_{i}, \theta_{i}\right)\right)}{\left(1-l_{i}\right) \operatorname{Var}\left(I\left(\mathbf{x}_{a}, s, \theta\right)\right)}\right)^{2}
$$

where $l_{i}$ are the diagonal terms of the matrix $\widehat{\zeta}\left(\widehat{\zeta} \widehat{\zeta}^{\mathrm{T}}\right)^{-1} \widehat{\zeta}^{\mathrm{T}}$ with $\widehat{\zeta}$ being the matrix constituted by the columns of $\zeta$ corresponding to the sparse indices set $\mathcal{K}\left(\mathbf{x}_{a}\right)$.

\subsection{Results}

The metamodel is independently constructed for each scenario in Table 2 because the random input space varies from a case to another. The first order marginal and the joint PDFs of two components $(y$ and $\psi$ ) of the random field $\mathbf{u}$, defined in Section 4.1, concerning the operating scenarios in Table 2 are shown in Fig. 9. It can be observed as the random space statistics vary from one case to another meaning that the simulations used to construct the metamodel related to one case cannot be employed for another metamodel.

\subsubsection{Rail fatigue index}

By choosing a maximal polynomial degree equal to 3, a complete PCE basis for a 10dimensional random space is composed by 286 terms. After the reduction only a few terms are retained in the metamodel. The number of terms $T^{\prime}\left(\mathbf{x}_{a}\right)$, in Eqn. (21), varies in the rail section area. For all the considered operating scenarios this number varies 

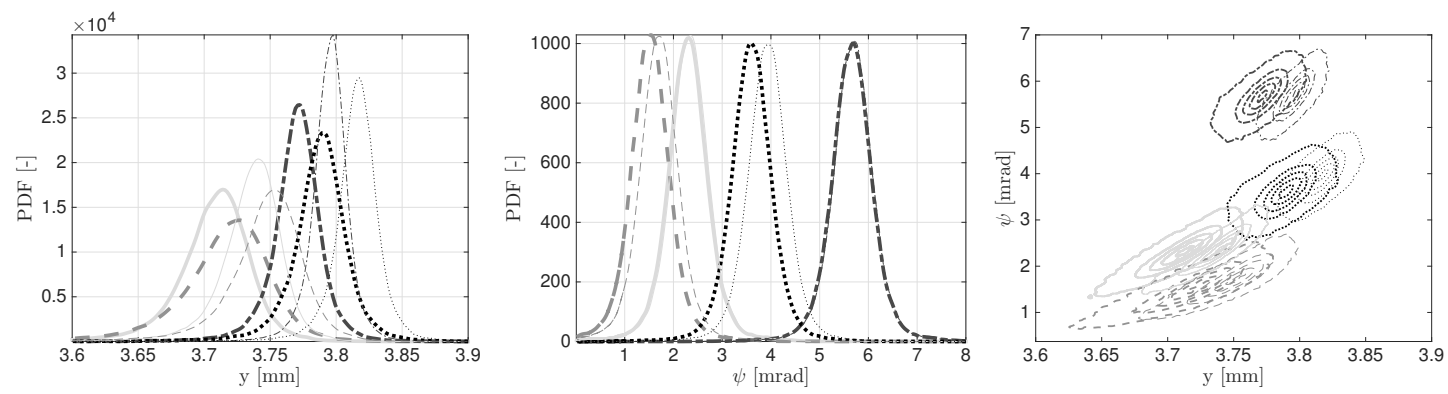

Figure 9. First order marginal and the joint PDFs of the components $y$ and $\psi$ of the random field $\mathbf{u}$ for the test cases with empty (thick lines) and full (thin lines) vehicle: slow wide curve (solid very light gray), fast wide curve (dashed light gray), slow tight curve (dashed-dotted dark gray), fast tight curve (dotted black).

between 6 and 44 .

The mean value and the coefficient of variation, on the track curvilinear abscissa $s$, of the fatigue index random field $I\left(\mathbf{x}_{a}, s, \theta\right)$, whose realisations are obtained by propagating the uncertainties using the metamodel of Eqn. (15), are shown in Fig. 10 and Fig. 11 for the two most different test cases. All the other operating scenarios are situated between these two cases. The highest values of the fatigue index are related to the contact patch on the wheel flange, that corresponds to the largest values of normal and tangential surface stresses. This is the region that mostly interests the rail fatigue.

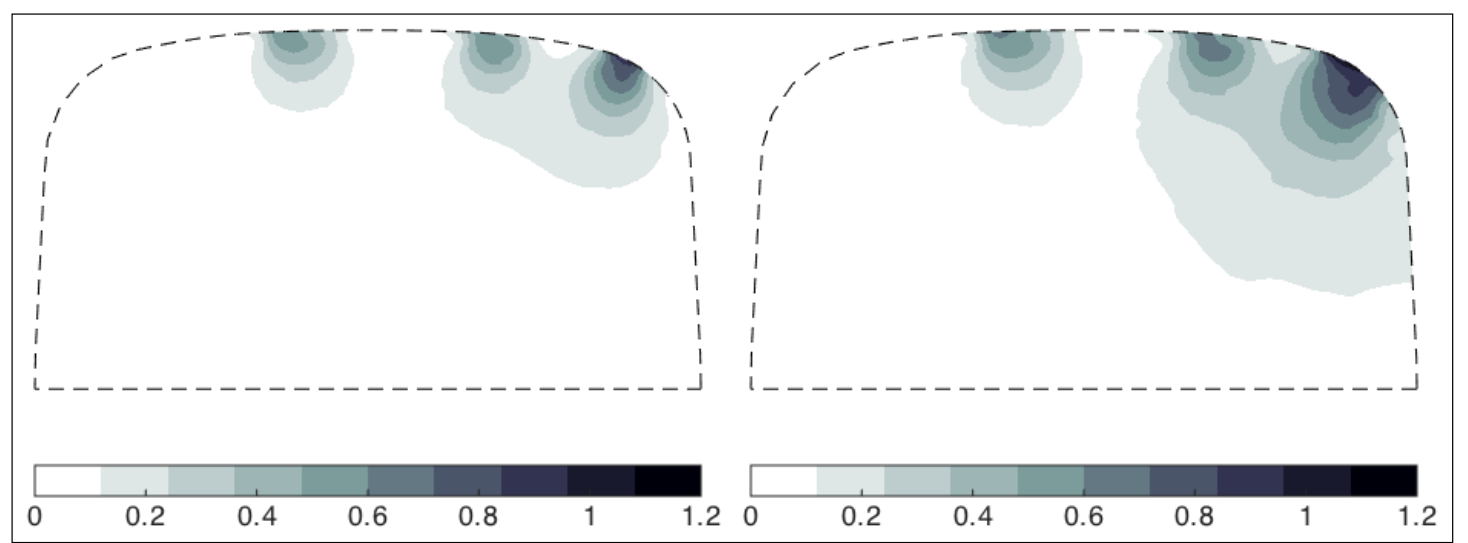

Figure 10. Mean value of the fatigue index in the rail section: empty slow vehicle, wide curve (left); full fast vehicle, tight curve (right).

The fatigue index takes high values only in the rail section regions close to the contact patch. The maximal value of the index on the rail section is the most important quantity which would represent the first crack starting propagating. The PDFs of the maximal fatigue index are shown in Fig. 12 and its mean value and coefficient of variation are shown in Table 10. Note that this quantity is always larger than 1 . The pdf shifts towards highest values when the curve is tighter and the velocity the largest one (increase of the contact forces). Moreover, the distribution is wider when the velocity increases.

The sensitivity indices concerning the maximal value of the fatigue index on the rail section are listed in Table 10. The most important parameters are the horizontal curvature in the $1000 \mathrm{~m}$ radius curve and the gauge in the tighter curve, followed by superelevation. The most impacting components of the input of the metamodel are the wheel lateral position $y$ followed by the yaw angle $\psi$ and the vertical wheel-rail position $z$. As shown in Section 4.4, this lateral position is mostly influenced by the horizontal curvature (1000 $\mathrm{m}$ curve radius) and the gauge (450 m curve radius) irregularities. The same tendency 


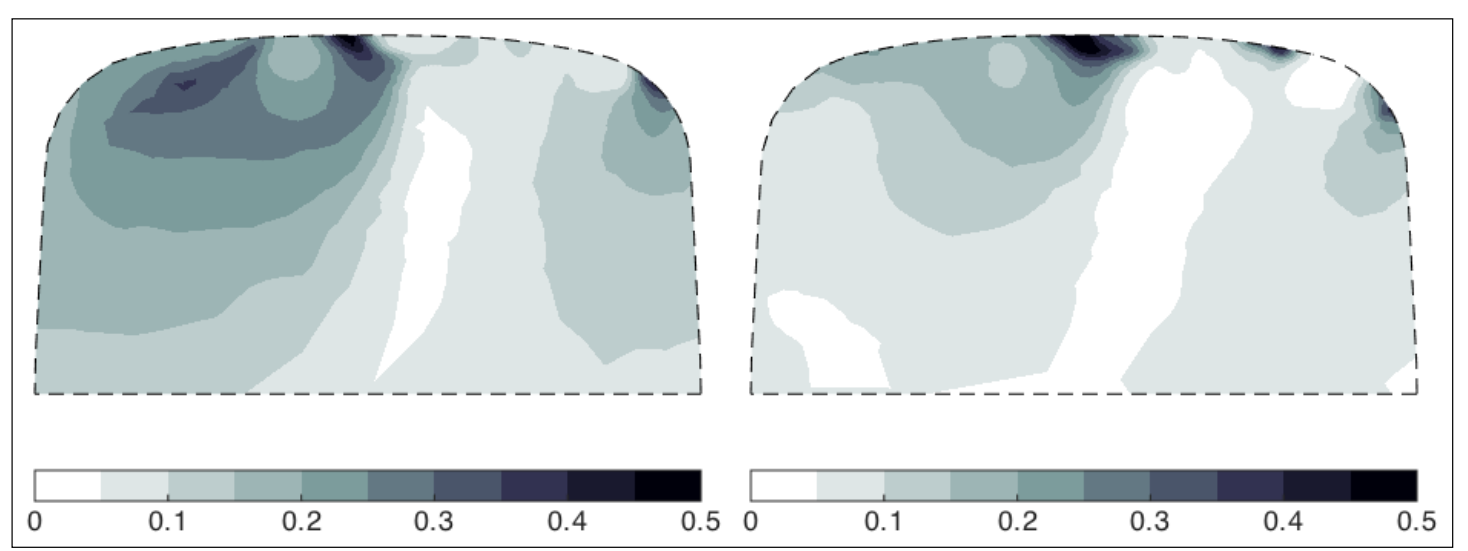

Figure 11. Coefficient of variation of the fatigue index in the rail section: empty slow vehicle, wide curve (left); full fast vehicle, tight curve (right).
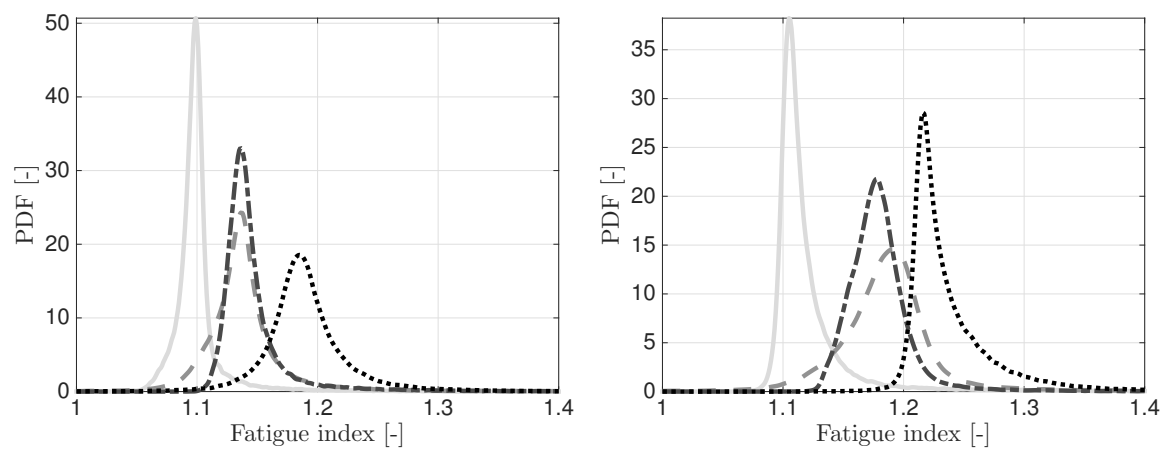

Figure 12. PDFs of the maximal value of the fatigue index: slow wide curve (solid very light gray), fast wide curve (dashed light gray), slow tight curve (dashed-dotted dark gray), fast tight curve (dotted black); empty (left) and full (right) vehicle.

is observed for the fatigue index. The sensitive index related to the superelevation is between $6 \%$ and $19 \%$ and tends to increase in the full vehicle test cases.

\subsubsection{Life cycles}

The relation between fatigue index and number of fatigue life, Eqn. (11), is non-linear monotonically decreasing function. Note that the statistics of this random variable are not finite since the number of cycles tends toward infinity when the fatigue criterion is smaller than 1 . For this reason, in this paragraph, the conditioned random variable $C^{\star}\left(s_{i}\right)$ is considered for the computation of the statistics and the sensitivity indices. It is defined as:

$$
\mathrm{P}\left(C^{\star}\left(s_{i}\right)\right)=\mathrm{P}\left(C\left(s_{i}\right) \mid \max _{\mathbf{x}_{a}}\left(I\left(\mathbf{x}_{a}, s_{i}\right)\right)>1\right)
$$

The PDFs of the number of life cycles are shown in Fig. 13 and its mean value and coefficient of variation are shown in Table 11. The PDF shifts towards lowest values when the curve is tighter and the velocity larger (increase of the contact forces). Moreover, the distribution is wider when the velocity increases.

The sensitivity indices are shown in Table 11. The standard deviation is smaller in the tight curve (contact position more stable) and becomes slightly larger when the train is empty. As for the fatigue index, the most influent parameters are the horizontal curvature (1000 $\mathrm{m}$ curve radius) and the gauge (450 $\mathrm{m}$ curve radius). The effect of superelevation 
Table 10. Mean $(\mu)$, coefficient of variation $\left(C_{V}\right)$ and 1st and 2nd order Sobol indices of the maximal value of the fatigue index on the rail section. Parameters whose indices are always smaller than 0.1 are not shown.

\begin{tabular}{|c|c|c|c|c|c|c|c|c|}
\hline & $\begin{array}{l}\text { Wide } \\
\text { Slow } \\
\text { Empty }\end{array}$ & $\begin{array}{l}\text { Wide } \\
\text { Fast } \\
\text { Empty }\end{array}$ & $\begin{array}{l}\text { Tight } \\
\text { Slow } \\
\text { Empty }\end{array}$ & $\begin{array}{l}\text { Tight } \\
\text { Fast } \\
\text { Empty }\end{array}$ & $\begin{array}{l}\text { Wide } \\
\text { Slow } \\
\text { Full }\end{array}$ & $\begin{array}{l}\text { Wide } \\
\text { Fast } \\
\text { Full }\end{array}$ & $\begin{array}{l}\text { Tight } \\
\text { Slow } \\
\text { Full }\end{array}$ & $\begin{array}{l}\text { Tight } \\
\text { Fast } \\
\text { Full } \\
\end{array}$ \\
\hline $\begin{array}{l}\bar{I} \\
\Sigma\end{array}$ & 1.10 & 1.13 & 1.14 & 1.18 & 1.11 & 1.17 & 1.18 & 1.23 \\
\hline $\overrightarrow{0}$ & 0.02 & 0.03 & 0.03 & 0.03 & 0.03 & 0.04 & 0.02 & 0.03 \\
\hline \multicolumn{9}{|c|}{ 1st order sensitivity indices } \\
\hline 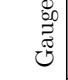 & 0.27 & 0.20 & 0.74 & 0.62 & 0.18 & 0.21 & 0.67 & 0.57 \\
\hline $\begin{array}{l}\vec{d} \\
\vec{d} \\
\dot{d}\end{array}$ & 0.07 & 0.06 & 0.08 & 0.11 & 0.10 & 0.14 & 0.12 & 0.19 \\
\hline$\underset{ت}{ت}$ & 0.52 & 0.43 & 0.12 & 0.16 & 0.63 & 0.43 & 0.13 & 0.14 \\
\hline 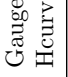 & 0.06 & 0.11 & 0.02 & 0.03 & 0.05 & 0.10 & 0.02 & 0.02 \\
\hline
\end{tabular}
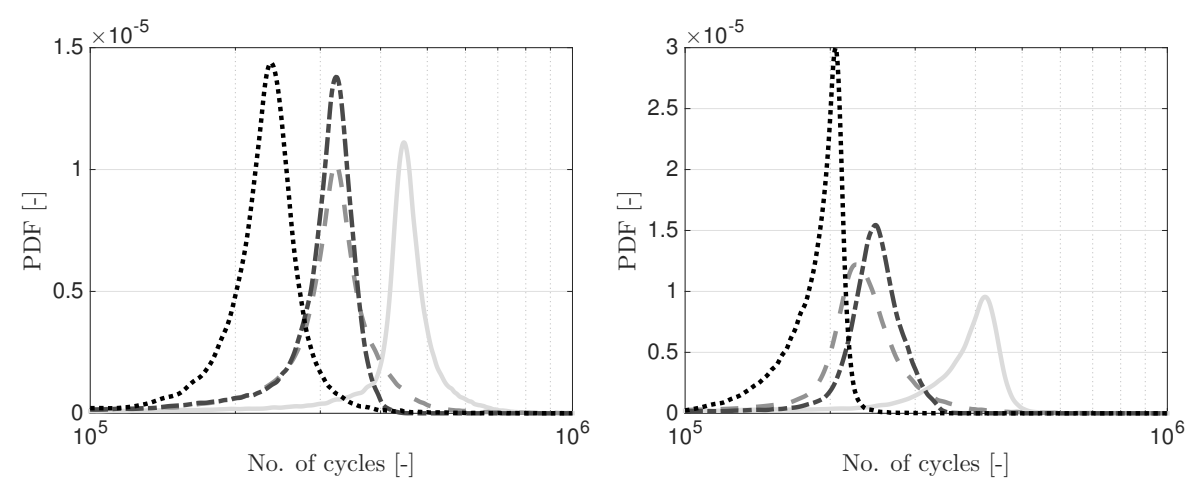

Figure 13. PDFs of the number of life cycles: slow wide curve (solid very light gray), fast wide curve (dashed light gray), slow tight curve (dashed-dotted dark gray), fast tight curve (dotted black); empty (left) and full (right) vehicle.

is not negligible, but smaller than the irregularities in the horizontal track plane. As shown for the dynamical quantities of interest, at higher velocity, the rail-wheel relative position variations are slightly larger. Therefore, the contact patches locations variations are slightly more important and influenced by a combination of parameters. This means that the values of the 2 nd (and higher orders) indices increase at the higher velocity. The 1st order indices are shown in Fig. 14 in box-plots obtained by bootstrapping. In that figure, on each box, the central mark indicates the median value of the index, the top and bottom edges of the box indicate the 75 th and 25 th percentiles, respectively and the whiskers extend to the most extreme values.

\section{Conclusion}

The steps to lead to a stochastic characterisation of the track geometry irregularities of a railway network are presented in this paper. A large set of experimental measurements 
Table 11. Mean $(\mu)$, coefficient of variation $\left(C_{V}\right)$ and 1st and 2nd order Sobol indices of the number of life cycles of the rail. Mean value expressed in $10^{5}$ cycles. Parameters whose indices are always smaller than 0.1 are not shown.

\begin{tabular}{|c|c|c|c|c|c|c|c|c|}
\hline & $\begin{array}{l}\text { Wide } \\
\text { Slow } \\
\text { Empty }\end{array}$ & $\begin{array}{l}\text { Wide } \\
\text { Fast } \\
\text { Empty }\end{array}$ & $\begin{array}{l}\text { Tight } \\
\text { Slow } \\
\text { Empty }\end{array}$ & $\begin{array}{l}\text { Tight } \\
\text { Fast } \\
\text { Empty }\end{array}$ & $\begin{array}{l}\text { Wide } \\
\text { Slow } \\
\text { Full }\end{array}$ & $\begin{array}{l}\text { Wide } \\
\text { Fast } \\
\text { Full }\end{array}$ & $\begin{array}{l}\text { Tight } \\
\text { Slow } \\
\text { Full } \\
\end{array}$ & $\begin{array}{l}\text { Tight } \\
\text { Fast } \\
\text { Full } \\
\end{array}$ \\
\hline $\begin{array}{l}\stackrel{8}{o} \\
\stackrel{1}{x} \\
z \\
z\end{array}$ & 4.54 & 3.30 & 3.11 & 2.39 & 3.82 & 2.47 & 2.50 & 1.90 \\
\hline$\vec{z}$ & 0.18 & 0.26 & 0.16 & 0.23 & 0.20 & 0.28 & 0.15 & 0.13 \\
\hline \multicolumn{9}{|c|}{ 1st order sensitivity indices } \\
\hline 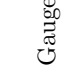 & 0.13 & 0.14 & 0.64 & 0.61 & 0.02 & 0.14 & 0.65 & 0.61 \\
\hline $\begin{array}{l}\frac{\vec{u}}{0} \\
\dot{d}\end{array}$ & 0.02 & 0.06 & 0.15 & 0.03 & 0.00 & 0.03 & 0.03 & 0.02 \\
\hline 苞 & 0.70 & 0.52 & 0.06 & 0.10 & 0.67 & 0.56 & 0.05 & 0.00 \\
\hline 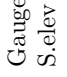 & 0.00 & 0.00 & 0.00 & 0.00 & 0.09 & 0.00 & 0.06 & 0.10 \\
\hline 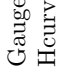 & 0.09 & 0.07 & 0.00 & 0.15 & 0.04 & 0.13 & 0.11 & 0.00 \\
\hline
\end{tabular}

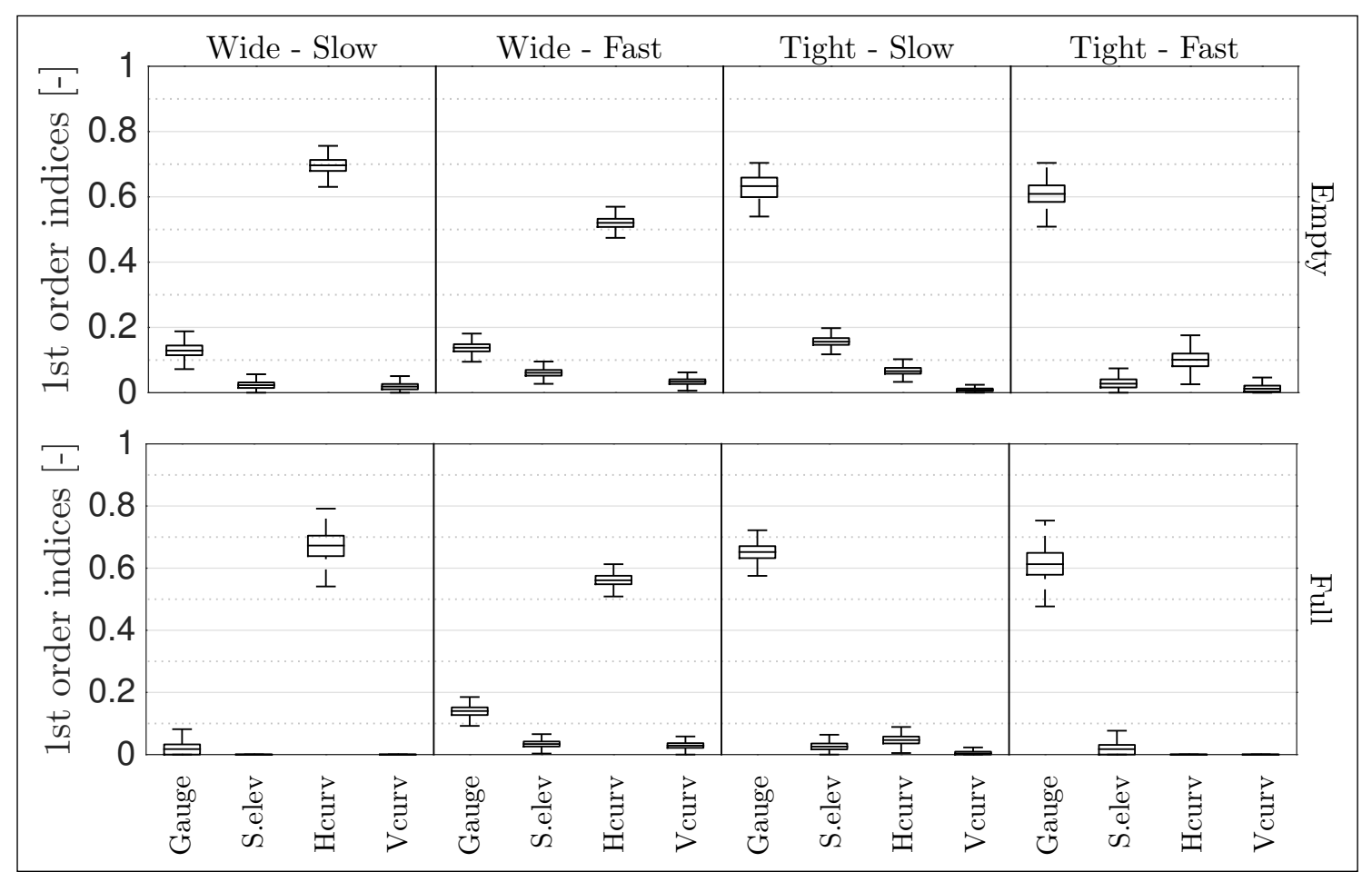

Figure 14. Box-plot representation of the 1st order sensitivity indices on the number of life cycles.

is used to model the irregularities as random fields. The model is able to capture the statistical and the spatial variability of the irregularities on the considered track.

A first sensitivity analysis concerning some dynamical quantities of interest is presented 
to highlight the effect of each random field representing the track irregularities. The superelevation irregularity is most influent for the quantities concerning the vertical vehicle dynamics: vertical position of the wheel and vertical contact force. The other quantities of interest are influenced by the horizontal curvature and the gauge, whose the importance increases in a tight curve.

A stochastic model of the rail fatigue is then constructed by means of numerical simulations. A PCE metamodelling technique allows to reduce the number of expensive numerical simulations needed to build the random model. This rail fatigue model can be used to improve the railway network maintenance. Indeed, a sensitivity analysis study is performed by means of this model in order to identify which kind of irregularities affects the rail life. The coefficient of variation of the number of fatigue cycles varies between 0.13 and 0.28 in all the presented operating scenarios. In a wide curve, the most influent irregularities is the horizontal curvature, while, in a tight curve, the gauge becomes determinant. A similar result has been found in [20] where, using a different approach, it is shown that the impact horizontal curvature on the rail fatigue is strong in the wide curves and becomes weaker when the curve radius decreases. However, in all the operating scenario the rail fatigue life is affected by the irregularities concerning the horizontal geometry.

\section{References}

[1] Iwnicki S. Handbook of Railway Vehicle Dynamics. Taylor \& Francis; 2006.

[2] Bigoni D, True H, Engsig-Karup AP. Sensitivity analysis of the critical speed in railway vehicle dynamics. Vehicle System Dynamics. 2014;51(sup1):37-41.

[3] Bideleh MMS, Berbyuk V. Global sensitivity analysis of bogie dynamics with respect to suspension components. Multibody System Dynamics. 2016;37:145-174.

[4] Suarez B, Felez J, Maroto J, Rodriguez P. Sensitivity analysis to assess the influence of the inertial properties of railway vehicle bodies on the vehicle's dynamic behaviour. Vehicle System Dynamics. 2013;51(2):1-29.

[5] Zakeri JA, Xia H. Sensitivity analysis of track parameters on train-track dynamic interaction. Journal of Mechanical Science and Technology. 2008;22(7):1299-1304.

[6] Zakeri Ja, Fathali M, Roudsari NB. Effects of Rail Cant on Wheel-Rail Contact Forces in Slab Tracks. International Journal of Mechanics and Applications. 2011;1(1):12-21.

[7] Grassie S. Measurement of railhead longitudinal profiles: a comparison of different techniques. Wear. 1996;191:245-251.

[8] Fröhling RD. Measurement, interpretation and classification of South African track geometry. Vehicle System Dynamics. 1995;24(Supplement 1):133-145; doi:10.1080/00423119508969620.

[9] Haigermoser A, Luber B, Rauh J, Gräfe G. Road and track irregularities: measurement, assessment and simulation. Vehicle System Dynamics. 2015;53(7):878-957.

[10] Nielsen J, Berggren E, Lölgen T, Müller R, Stallaert B, Pesqueux L. Overview of Methods for Measurement of Track Irregularities Important for Ground-Borne Vibration. Railway Induced Vibration Abatement Solutions; 2013. Report No.: SCP0-GA-2010-265754.

[11] Gullers P, Andersson L, Lundén R. High-frequency vertical wheel-rail contact forces-Field measurements and influence of track irregularities. Wear. 2008;265(9-10):1472-1478.

[12] Lestoille N, Soize C, Funfschilling C. Sensitivity of train stochastic dynamics to long-time evolution of track irregularities. Vehicle System Dynamics. 2016;54(5):545-567.

[13] Lei X, Noda NA. Analyses of dynamic response of vehicle and track coupling system with random irregularity of track vertical profile. Journal of Sound and Vibration. 2002;258(1):147-165.

[14] Sun YQ, Roach D. Effect of track geometry irregularities on wheel-rail impact forces. In: Conference on Railway Engineering. Darwin; 2004.

[15] Zhai W, Wang K, Cai C. Fundamentals of vehicle-track coupled dynamics. Vehicle System Dynamics. 2009;47(11):1349-1376.

[16] Perrin G, Soize C, Duhamel D, Funfschilling C. Quantification of the influence of the track geometry variability on the train dynamics. Mechanical Systems and Signal Processing. 2015;60:945-957. 
[17] Yang X, Gu S, Zhou S, Yang J, Zhou Y, Lian S. Effect of track irregularity on the dynamic response of a slab track under a high-speed train based on the composite track element method. Applied Acoustics. 2015;99:72-84.

[18] Xu L, Zhai W, Gao J. A probabilistic model for track random irregularities in vehicle/track coupled dynamics. Applied Mathematical Modelling. 2017;51:145-158.

[19] Evans JR, Burstow MC. Vehicle / track interaction and rolling contact fatigue in rails in the UK. Vehicle System Dynamics. 2006;44:708-717.

[20] Karttunen K, Kabo E, Ekberg A. The influence of track geometry irregularities on rolling contact fatigue. Wear. 2013;314(1-2):78-86.

[21] Li Z, Zhao X, Esveld C, Dollevoet R, Molodova M. An investigation into the causes of squats Correlation analysis and numerical modeling. Wear. 2008;265:1349-1355.

[22] Iyengar BRN, Jaiswap OR. Random field modeling of track irregularities. Journal of Tranport ation Engineering. 1995;121:303-308.

[23] Zhu M, Cheng X, Miao L, Sun X, Wang S. Advanced Stochastic Modeling of Railway Track Irregularities. Advances in Mechanical Engineering. 2013;.

[24] Perrin G, Soize C, Duhamel D, Funfschilling C. Track irregularities stochastic modeling. Probabilistic Engineering Mechanics. 2013;34:123-130.

[25] Claus H, Schiehlen W. Modeling and Simulation of Railway Bogie Structural Vibrations. Vehicle System Dynamics. 1998;29(sup1):538-552; doi:10.1080/00423119808969585.

[26] Majka M, Hartnett M. Dynamic response of bridges to moving trains: A study on effects of random track irregularities and bridge skewness. Computers and Structures. 2009;87(19-20):1233-1252.

[27] Xu L, Zhai W. Stochastic analysis model for vehicle-track coupled systems subject to earthquakes and track random irregularities. Journal of Sound and Vibration. 2017;407:209-225.

[28] Shinozuka M, Deodatis G. Simulation of stochastic processes by spectral representation. Applied Mechanics Reviews. 1991;44(4):191-204; doi:10.1115/1.3119501.

[29] Panunzio AM, Puel G, Cottereau R, Simon S, Quost X. Construction of a stochastic model of track geometry irregularities and validation through experimental measurements of dynamic loading. Vehicle System Dynamics. 2017;55(3):399-426.

[30] McRae GJ, Tilden JW, Seinfeld JH. Global sensitivity analysisa computational implementation of the Fourier Amplitude Sensitivity Test (FAST). Computers \& Chemical Engineering. 1982;6(1):1525 .

[31] Sobol I. Sensitivity Estimates for Nonlinear Mathematical Models. Mathematical Modeling and Computational experiment. 1993;1(4):407-414.

[32] Saltelli A. Making best use of model evaluations to compute sensitivity indices. Computer Physics Communications. 2002;145:280-297.

[33] Cottereau R, Rochinha FA, Coutinho ALGA. Comparison of two parameterizations of a turbulenceinduced flocculation model through global sensitivity analysis. Continental Shelf Research. 2014; 85:85-95.

[34] Pombo J, Ambrósio J. An alternative method to include track irregularities in railway vehicle dynamic analyses. Nonlinear Dynamics. 2012;68(1-2):161-176.

[35] Luber B, Haigermoser A, Grabner G. Track geometry evaluation method based on vehicle response prediction. Vehicle System Dynamics. 2010;48(sup1):157-173; doi:10.1080/00423111003692914.

[36] Li MXD, Berggren EG, Berg M, Persson I. Assessing track geometry quality based on wavelength spectra and track-vehicle dynamic interaction. Vehicle System Dynamics. 2008;46(sup1):261-276.

[37] Ayasse J, Chollet H. Determination of the wheel rail contact patch in semi-Hertzian conditions. Vehicle System Dynamics. 2005;43(3):161-172.

[38] Johnson KL. Contact Mechanics. Cambridge: Cambridge University Press; 1985; doi:10.1017/CBO9781139171731.

[39] Kapoor A, Johnson KL. Effect of changes in contact geometry on shakedown of surfaces in rolling/sliding contact. International Journal of Mechanical Sciences. 1992;34(3):223-239; doi:10.1016/0020-7403(92)90073-P.

[40] Clayton P. Tribological aspects of wheel-rail contact: a review of recent experimental research. Wear. 1995;191(1996):170-183; doi:10.1016/0043-1648(95)06651-9.

[41] Ekberg A, Kabo E. Fatigue of railway wheels and rails under rolling contact and thermal loading-an overview. Wear. 2005;258(7-8):1288-1300; doi:10.1016/j.wear.2004.03.039.

[42] Olofsson U, Lewis R. Tribology of the wheel-rail contact. In: Iwnicki S, editor. Handbook of railway vehicle dynamics. Chapter 5; CRC Press - Taylor \& Francis Group; 2006. p. 121-141.

[43] Dang Van K, Maitournam M. Steady-state flow in classical elastoplasticity: Applications to repeated rolling and sliding contact. Journal of the Mechanics and Physics of Solids. 1993;41(1993):1691-1710. 
[44] Dang Van K, Griveau B, Message O. On a new multiaxial fatigue limit criterion: theory and applications. In: Brow MW, Miller KJ, editors. Biaxial and multiaxial fatigue. Vol. 3; London: Mechanical Engineering Pubblications; 1989. p. 479-496.

[45] Dang Van K, Maitournam MH. On some recent trends in modelling of contact fatigue and wear in rail. Wear. 2002;253:219-227; doi:10.1016/S0043-1648(02)00104-7.

[46] Burstow M. Whole Life Rail Model application and development. Continued development of an RCF damage parameter. Rail Safety and Standards Board; 2003. Report No.: AEATR-ES-2003-832.

[47] Hiensch M, Steenbergen M. Rolling Contact Fatigue on premium rail grades: Damage function development from field data. Wear. 2017;to appear.

[48] Trummer G, Marte C, Dietmaier P, Sommitsch C, Six K. Modeling surface rolling contact fatigue crack initiation taking severe plastic shear deformation into account. Wear. 2016;352-353:136-145.

[49] Solano-Alvarez W, Peet MJ, Pickering EJ, Jaiswal J, Bevan A, Bhadeshia HK. Synchrotron and neural network analysis of the influence of composition and heat treatment on the rolling contact fatigue of hypereutectoid pearlitic steels. Materials Science and Engineering A. 2017;707(September):259269.

[50] Makino T, Neishi Y, Shiozawa D, Kikuchi S, Okada S, Kajiwara K, Nakai Y. Effect of defect shape on rolling contact fatigue crack initiation and propagation in high strength steel. International Journal of Fatigue. 2016;92:507-516.

[51] Ekberg A, Kabo E, Lundén R, Matsui M. Stress gradient effects in surface initiated rolling contact fatigue of rails and wheels. Wear. 2016;366-367:188-193.

[52] Steenbergen M. Rolling contact fatigue in relation to rail grinding. Wear. 2016;356-357:110-121.

[53] Yang W, Huang Y, Zhou Q, Wang J, Jin X, Keer LM. Parametric study on stressed volume and its application to the quantification of rolling contact fatigue performance of heterogeneous material. Tribology International. 2017;107(September 2016):221-232.

[54] Loève M. Probability theory. 4th ed. Springer-Verlag; 1977.

[55] Ghanem RG, Spanos PD. Stochastic Finite Elements: A Spectral Approach. New York, NY: Springer New York; 1991.

[56] Sebès M, Chevalier L, Ayasse J, Chollet H. A fast-simplified wheelrail contact model consistent with perfect plastic materials. Vehicle System Dynamics: International Journal of Vehicle Mechanics and Mobility. 2012;50(9):1453-1471.

[57] Lin T. Analysis of elastic and plastic strains of a face-centred cubic crystal. Journal of the Mechanics and Physics of Solids. 1957;5(2):143-149; doi:10.1016/0022-5096(57)90058-3.

[58] Garnham JE, Davis CL. The role of deformed rail microstructure on rolling contact fatigue initiation. Wear. 2008;265(9-10):1363-1372; doi:10.1016/j.wear.2008.02.042.

[59] Desimone H, Bernasconi A, Beretta S. On the application of Dang Van criterion to rolling contact fatigue. Wear. 2006;260(4-5):567-572; doi:10.1016/j.wear.2005.03.007.

[60] Charkaluk E, Constantinescu A, Maitournam H, Dang Van K. Revisiting the dang van criterion. Procedia Engineering. 2009;1(1):143-146; doi:10.1016/j.proeng.2009.06.033.

[61] Papadopoulos I, Davoli P, C G, Filippini M, Bernasconi A. A comparative study of multiaxial high-cycle fatigue criteria for metals. International Journal of Fatigue. 1997;19(3):219-235.

[62] Efron B. The Jackknife, the Boostrap and Other Resampling Plans. Philadelphia, PA: Society for Industrial and Applied Mathematics; 1982.

[63] European Committee of Normalisation. A new and feasible way of homologating vehicles from a running dynamics point of view . European Railway Agency; 2016. European standard.

[64] Saltelli A, Andres T, Homma T. Sensitivity analysis of model output. Computational Statistics \& Data Analysis. 1993;15:211-238.

[65] Soize C, Ghanem R. Physical Systems with Random Uncertainties: Chaos Representations with Arbitrary Probability Measure. SIAM Journal on Scientific Computing. 2004 jan;26(2):395-410.

[66] Navarro M, Witteveen J, Blom J. Stochastic Collocation for Correlated Inputs. In: UNCECOMP 2015, 1st ECCOMAS Thematic Conference on Uncertainty Quantification in Computational Sciences and Engineering; May. Crete Island, Greece; 2015. p. 25-27.

[67] Berveiller M, Sudret B, Lemaire M. Stochastic finite element: a non intrusive approach by regression. European Journal of Computational Mechanics. 2006;15(October 2016):81-92.

[68] Blatman G, Sudret B. Adaptive sparse polynomial chaos expansion based on least angle regression. Journal of Computational Physics. 2011;230:2345-2367.

[69] Blatman G, Sudret B. An adaptive algorithm to build up sparse polynomial chaos expansions for stochastic finite element analysis. Probabilistic Engineering Mechanics. 2010;25:183-197. 